ISSN: 0213-2060

DOI: http://dx.doi.org/10.14201/shhme201432103130

\title{
INTERACCIÓN SOCIEDAD Y MEDIO AMBIENTE. EL ENTORNO DE LA LAGUNA DE LOS TOLLOS (ANDALUCÍA OCCIDENTAL), SIGLOS XIII AL XV ${ }^{\text {I }}$
}

\author{
Society and Environment Interaction. The Environment of the Laguna de los \\ Tollos (Western Andalusia), $13^{\text {th }}$ - $15^{\text {th }}$ Centuries
}

Emilio MARTÍN GUTIÉRREZ

Depto. de Historia, Geografía y Filosofía. Facultad de Filosofia y Letras. Universidad de Cádiz. Avda. Gómez Ulla, s/n.E-11003 CADIZ.C. e.: emilio.martin@uca.es

Recibido: 2014-01-21

Revisado: 2014-09-26

Aceptado: 2014-10-03

BIBLID [0213-2060(2014)32;103-130]

RESUMEN: Se estudia el entorno de la laguna de los Tollos (Andalucía Occidental) entre los siglos XIII y XV. La investigación, que tiene como objetivo analizar la interacción sociedad medio ambiente, se enmarca dentro de un proyecto en el que se profundizará en el conocimiento de los humedales en este espacio geográfico. En esos ecosistemas las comunidades campesinas se aprovecharon junto a sus tierras de cultivo de los recursos cinegéticos, pastoriles, pesqueros y recolectores en los espacios ribereńos. El período cronológico elegido incluye un amplio conjunto de transformaciones que tuvieron una incidencia directa en la gestación y organización de los paisajes rurales.

Palabras clave: Sociedad. Medio Ambiente. Laguna de los Tollos. Siglos XIII-Xv. Andalucía Occidental.

1 Esta investigación se ha realizado dentro del Proyecto «Paisaje agrario y sociedad rural en Extremadura y Andalucía Occidental (siglos XV-XvI)» HAR2010-15238.

Abreviaturas utilizadas: AMJF = Archivo Municipal de Jerez de la Frontera. AHR = Archivo Histórico Reservado. $\mathrm{ARChG}=$ Archivo de la Real Chancillería de Granada. 
EMILIO MARTÍN GUTIÉRREZ

\section{INTERACCIÓN SOCIEDAD Y MEDIO AMBIENTE. EL ENTORNO DE LA LAGUNA DE LOS TOLLOS \\ (ANDALUCÍA OCCIDENTAL), SIGLOS XIII AL XV}

ABSTRACT: Environment of the Laguna de los Tollos is studied between $13^{\text {th }}$ and $15^{\text {th }}$ Centuries. The research, which aims to analyse the interaction environment-society, is part of a project that will deepen the knowledge of wetlands in this geographical area. In these ecosystems rural communities took advantage with their farmland for hunting, herding, fishing and gathering resources in riparian areas. The chosen chronological period includes a wide range of changes that had a direct impact on the management and organization of rural landscapes.

Keywords: Society. Environment. Laguna de los Tollos. $13^{\text {th }}-15^{\text {th }}$ Centuries. Western Andalusia.

SUMARIO: 0 Planteamiento de la problemática. 1 El paisaje de la laguna de los Tollos y su entorno. 1.1 Los cambios en la fisonomía del territorio: de un espacio lacustre a uno marismeño. 1.2 El funcionamiento del humedal: cursos fluviales y acuíferos. 1.3 Las características edafológicas. 1.4 La sierra de Gibalbín. 2 La interacción sociedad y medio ambiente: siglos XIII al XV. 2.1 El poblamiento rural en el entorno de la laguna de los Tollos. 2.2 El aprovechamiento de los recursos hídricos: pozos, fuentes, tollos y lagunas. 2.3 Entre marismas y humedales: aprovechamientos pastoriles y cinegéticos. 2.4 El Cuervo: de poblado a donadío y dehesa. 3 Conclusiones.

\section{Planteamiento de la Problemática ${ }^{2}$}

Que sy los vezinos e la dicha villa de Vtrera o de otras partes de tierra de Sivilla se estavan, que no se yvan fuera del término de la dicha villa de Librixa después que mediava el mes de abril, los vezinos de la dicha villa e los pastores [...] les defendían las dichas aguas. E la dicha villa de Librixa ponia guardas [...] e prendavan a las personas que heran rebeldes e entravan a agostar e bever las aguas de los dichos pozos.

Domingo Ruiz, entre 30 y 34 ańos de edad ${ }^{3}$.

Mientras escribía el artículo, leía con atención el libro Guerras climáticas de Harald Welzer donde plantea la cuestión medioambiental y su vinculación con el cambio climático en los inicios del siglo xxi. El valor del agua como recurso escaso y los conflictos por su control adquieren una dimensión notable en esas páginas ${ }^{4}$. Sus valoraciones constituyen un ejemplo de cómo la preocupación por el deterioro del medio ambiente ha ido calando en la sociedad y aflorando entre los historiadores durante las dos últimas décadas 5 .

2 Agradezco los comentarios y aportaciones de Manuel Cabaco Cordero de la Agencia del Agua y Medio Ambiente de la Junta de Andalucía y coordinador del proyecto LIFE+ Los Tollos.

3 El 22 de julio de 1532 Juan Rodríguez Hinojosa, en nombre de Lebrija, presentaba un memorial con los «nonbres de çiertos pozos e fuentes e toyos que ay en el término de la dicha villa». Uno de los testigos fue Domingo Ruiz. ARChG, Pleito Utrera-Lebrija, Cabina 512, Leg. 2378, pieza 2, s/f.

4 Welzer, Harald. Guerras climáticas. Por qué mataremos (y nos matarán) en el siglo XXI. Barcelona: Katz, 2010.

5 Campillo, Antonio. Variaciones de la vida humana. Una teoría de la Historia. Madrid: Akal, 2001, pp. 419-428. González de Molina, Manuel. «Argumentos ambientales para la renovación de la Historia 
EMILIO MARTÍN GUTIÉRREZ

INTERACCIÓN SOCIEDAD Y MEDIO AMBIENTE. EL ENTORNO DE LA LAGUNA DE LOS TOLLOS

(ANDALUCÍA OCCIDENTAL), SIGLOS XIII AL XV

Aunque sea de una manera esquemática, resulta conveniente el planteamiento del estado de la cuestión subrayando las líneas más apropiadas para profundizar en el conocimiento de esta problemática.

El medio ambiente en su visión integral es el resultado de una continua interacción entre factores bióticos y abióticos. Un planteamiento ecológico que reflexiona sobre «le forme dell'ambiente» $\mathrm{y}$ «le forme dell'habitat» y que relaciona las transformaciones y cambios en un ecosistema ${ }^{6}$. En 2002 Robert Delort y François Walter publicaban una síntesis sobre la historia del medio ambiente en Europa donde planteaban propuestas de estudios ${ }^{7}$. Son muy

Agraria». Vínculos de Historia. Dossier Monográfico. El agua en la Historia: usos, técnicas y debates, 2012, vol. 1, pp. 95-114, <http://vinculosdehistoria.com/numeros-completos/vdh1.pdf> [consulta 01/07/2013]. CLEMENTE Ramos, Julián. "La evolución del medio natural en Extremadura (c. 1142-c. 1525)». En Clemente Ramos, Julián (ed.). El medio natural en la España Medieval. Actas del I Congreso sobre Ecohistoria e Historia Medieval. Cáceres: Universidad, 2001, pp. 15-56. Furió, Antoni. «La domesticación del medio natural. Agricultura, ecología y economía en el País Valenciano en la Baja Edad Media». En Clemente Ramos (ed.), El medio natural en la España medieval, pp. 57-103. Torró, Josep y Guinot, Enric (eds.). Hidráulica agraria y sociedad feudal. Prácticas, técnicas y espacios. Valencia: Universidad, 2102. Sabaté, Flocel (ed.). Natura i desenvolupament. El medi ambient a l'Edat Mitjana. XI Curs d'estiu Comtat d'Urgell (12, 13 i 14 juliol de 2006). Lleida: Pagès, 2007. Borrero Fernández, Mercedes. «La acción del hombre sobre el medio natural: paisaje agrario y ordenanzas rurales en el reino de Sevilla de 1350 a 1500». En Borrero Fernández, Mercedes. Mundo rural y vida campesina en la Andalucía medieval. Granada: Universidad, 2003, pp. 413-448. Martín Gutiérrez, Emilio. La organización del paisaje rural durante la Baja Edad Media. El ejemplo de Jerez de la Frontera. Sevilla: Universidad, 2004. Montanari, Massimo. «La foresta come spazio economico e culturale». En Uomo e spazio nell'alto Medioevo. Settimane di Studio del Centro Italiano di Studi sull'alto Medioevo. 4-8 aprile 2002. Spoleto: Centro Italiano di Studi sull'alto Medioevo, 2003, pp. 301-340. Galetti, Paola (a cura di). Paesaggi, comunità, villaggi medievali. Atti del Convegno internazionale di studio. Bologna, 14-16 gennaio 2010. 2 vols. Spoleto: Centro Italiano di Studi sull'alto Medioevo, 2012. Malvolti, Alberto e Pinto, Giuliano (a cura di). Incolti, fumi e paludi. Utilizzazione delle risorse naturali nella Toscana medievale e moderna. Firenze: Leo S. Olschki Editore, 2003. Tosco, Carlo, Il paesaggio storico. Le fonti e i metodi di ricerca. Roma-Bari: Laterza, 2009. Delort, Robert. "Les facteurs éco-biologiques de l'espace: permanences et mutations». En Uomo e spazio nell'alto Medioevo, pp. 69-90. Wiскнам, Chris. "Espacio y sociedad en los conflictos campesinos en la Alta Edad Media». En Rodríguez, Ana (ed.). El lugar del campesino. En torno a la obra de Reyna Pastor. Valencia: Universidad, 2007, pp. 33-60. GLICK, Thomas. Paisajes de conquista. Cambio cultural y geográfico en la España medieval. Valencia: Universidad, 2007. Horden, Peregrine and Purcell, Nicholas. The corrupting sea. A study of Mediterranean History. Oxford: Blackwell Publishing, 2012, pp. 186-190. Olmo Herguedas, Emilio. Agua, paisaje y ecohistoria. La comarca de Cuéllar a partir del siglo XIII. Valladolid: Universidad, 2011.

6 Tosco, Il paesaggio storico, pp. 97-164. Cortonesi, Alfio e Montanari, Massimo (a cura di). Medievistica italiana e Storia Agraria. Risultati e prospettive di una stagione storiografica. Atti del Convegno di Montalcino, 12-14 dicembre 1997. Bologna: CLUEB, 2001, pp. 8-10. Clemente Ramos (ed.), El medio natural en la España Medieval. Pérez-Embid, Javier (ed.). La Andalucía medieval. Actas de las I Jornadas de Historia Rural y Medio Ambiente (Almonte, 23-25 mayo 2000). Huelva: Universidad, 2003. Martín Gutiérrez, Emilio (ed.). El paisaje rural en Andalucía Occidental durante los siglos bajomedievales. Actas de las I Jornadas Internacionales sobre paisajes rurales en época medieval. Cádiz, 1 y 2 de abril de 2009. Cádiz: Universidad, 2011.

7 Delort, Robert e Walter, François. Storia dell'ambiente europeo. Bari: Edizioni Dedalo, 2002. Con anterioridad Delort ya había propuesto una lectura de los factores bioecológicos en Europa Occidental entre los siglos v y xir: «en particulier la végétation, la faune, les microorganismes, l’homme biologique ou en société, sa réception des facteurs précédents et l'influence éventuelle de son action en retour sont indissociables»; Delort, Robert. «Les facteurs éco-biologiques». Un estado de la cuestión en Clément, François. "L’historien et les phénomènes naturels: un effort d'appropriation». En Clément, François (dir.). Histoire et nature. Pour 
EMILIO MARTÍN GUTIÉRREZ

INTERACCIÓN SOCIEDAD Y MEDIO AMBIENTE. EL ENTORNO DE LA LAGUNA DE LOS TOLLOS

(ANDALUCÍA OCCIDENTAL), SIGLOS XIII AL XV

sugerentes las reflexiones sobre el concepto Riparia y sus aproximaciones ecosistémicas que atienden a la interacción sociedad-medio ambiente identificando los espacios vulnerables a las variaciones climáticas. Ya que las riberas han tenido una ocupación secular, pueden ser consideradas zonas privilegiadas para su estudio. "La démographie, l'exploitation des ressources naturelles -afirma Ella Hermon- le développement technologique se rattachant à l'aménagement de ce milieu fragile influent sur sa dégradation progressive». El conocimiento de su historia es importante para las estrategias actuales de preservación de los bords de l'eau ${ }^{8}$. Centrados en la corona de Castilla sobresalen los proyectos liderados por María Isabel del Val que han ido viendo la luz en varias publicaciones prestando atención al estado de la cuestión en las historiografías italiana, francesa, inglesa y española?

Desde presupuestos culturales el agua ha tenido también un papel central en la investigación ${ }^{10}$. Elemento imprescindible para la vida ${ }^{11}$, fue percibida como una fuente de enfermedad o como una fuerza devastadora ${ }^{12}$. Aunque en las sociedades preindustriales hubo planteamientos que manifestaban la superioridad del Hombre ${ }^{13}$, fue el pensamiento

une histoire écologique des sociétés méditerranéennes (Antiquité et Moyen Âge). Rennes: Universitaires, 2011, pp. 9-22. Matheus, Michael et al. Le calamità ambientali nel Tardo Medioevo europeo: realtà, percezioni, reazioni. Atti del XII convegno del Centro di Studi sulla civiltà del Tardo Medioevo. S. Miniato, 31 maggio-2 giugno 2008. Firenze: University, 2010.

8 Hermon, Ella. «Riparia dans l'Empire Romain: pour la définition d'un concept». En Hermon, Ella (dir.). Riparia dans l'Empire Romain pour la définition du concept. Actes des Journées d'étude de Québec, 29-31 Octobre 2009. Oxford: John and Erica Hedges, 2010; y Société et climats dans l'Empire Romain. Pour une perspective historique et systémique de la gestion des ressources en eau dans l'Empire Romain. Napoli: Editoriale Scientifica, 2009.

9 Val Valdivieso, María Isabel del. «La culture de l'eau au Moyen Âge. Les villes de Castille». En Actes IX Symposium International de l'Eau. Cannes, 2007 (edición digital). ÍDEM. Agua y poder en la Castilla bajomedieval. El papel del agua en el ejercicio del poder concejil a fines de la Edad Media. Valladolid: Junta de Castilla y León, 2003. ÍDEm. El agua en las ciudades castellanas durante la Edad Media. Fuentes para su estudio. Valladolid: Universidad, 1998. Ídem (coord.). Vivir del agua en las ciudades medievales. Valladolid: Universidad, 2006. Val Valdivieso, María Isabel del y Bonachía Hernando, Juan Antonio (coords.). Agua y sociedad en la Edad Media hispana. Granada: Universidad, 2012.

10 Glacken, Clarence C. Huellas en la playa de Rodas. Naturaleza y cultura en el pensamiento occidental desde la Antigüedad al siglo XVIII. Barcelona: Ediciones del Serbal, 1996. ARNOLD, David. La naturaleza como problema histórico. El medio, la cultura y la expansión de Europa. México: FCE, 2000. Delort e Walter, Storia dell'ambiente, p. 85. Montanari, Massimo. "Il sapore dell'acqua». En Montanari, Massimo. Gusti del Medioevo. I prodotti, la cucina, la tavola. Roma-Bari: Laterza, 2012, pp. 136-154. BodeI, Remo. Paisajes sublimes. El hombre ante la naturaleza salvaje. Madrid: Siruela, 2011, pp. 90-99. Martínez DE Pisón, Eduardo. Miradas sobre el paisaje. Madrid: Biblioteca Nueva, 2009. Mata Olmo, Rafael y Fernández Muñoz, Santiago. "Paisajes y patrimonios culturales del agua. La salvaguarda del valor patrimonial de los regadíos tradicionales». Scripta Nova. Revista Electrónica de Geografía y Ciencias Sociales, vol. 337, n. ${ }^{\circ}$ XIV, 2010 <http://www.ub.es/geocrit/sn/sn-337.htm> [consultado 15/06/2013].

11 Isidoro de Sevilla. Etimologías. Madrid: BAC, 1995, p. 140. Herrera, Gabriel Alonso de. Obra de agricultura. Madrid: BAE, 1970, pp. 209-212. Delort e Walter, Storia dell'ambiente, pp. 162-171.

12 Jasper Schenk, Gerrit. «Disastri. Modelli interpretativi delle calamità naturali dal Medioevo al Rinascimento». En Matheus et al., Le calamità ambientali, pp. 42-65.

13 «Apoderarse deue el pueblo por fuerça de la tierra, quando non lo pudiessen fazer por maestría e por arte. Ca estonce, se deuen auenturar a vencer las cosas, por fuerça e por fortaleza, así como quebrantando las grandes peńas e foradando los grandes montes e allanando los logares altos e alçando los baxos o matando las animalias brauas e fuertes, aventurándose con ellas para aduzir su pro»; Alfonso X. Las Siete Partidas del 
EMILIO MARTÍN GUTIÉRREZ

INTERACCIÓN SOCIEDAD Y MEDIO AMBIENTE. EL ENTORNO DE LA LAGUNA DE LOS TOLLOS

(ANDALUCÍA OCCIDENTAL), SIGLOS XIII AL XV

ilustrado el que logró imponer la idea de que la ciencia y la técnica permitirían dominar a la Naturaleza $^{14}$. Posicionamientos que han llevado a los historiadores en sus investigaciones a primar el avance de las actividades roturadoras ${ }^{15}$.

Con frecuencia se ha insistido en los aspectos negativos de los humedales como nocivos para la salud. El discurso quedaba estructurado entre lo que había sido construido, cultivado o habitado y «lo que es propiamente salvaje», donde se incluían las zonas húmedas ${ }^{16}$. No es extraño, como señala Ella Hermon, que las zonas pantanosas fuesen vinculadas a los ambientes donde habitaban los pueblos que habían sido derrotados por los romanos ${ }^{17}$. Si esas imágenes encuentran sus raíces en la Antigüedad y durante la Antigüedad Tardía ${ }^{18}$, se fueron consolidando durante los siglos altomedievales. Porque, según Vito Fumagalli, la crisis del siglo vi contribuyó a su cristalización dejando una impronta indeleble en la sociedad occidental ${ }^{19}$. Son paradigmáticos los versos de Dante recreando el ambiente de Val di Chiana como lugar propenso a la malaria y al paludismo ${ }^{20}$. Por ello Braudel subrayaba que la lucha del hombre mediterráneo con las tierras bajas -eliminando aguas malsanas o introduciendo el riego- había constituido «el rasgo verdadero y original de su historia rural». Por el contrario, el bosque cenagoso fue el problema al que tuvieron que enfrentarse los pueblos del norte de Europa ${ }^{21}$.

Pero también hubo intentos por comprender el funcionamiento de esos ecosistemas. Uno de ellos viene de la mano del emperador Federico II de Hohenstaufen que describía los humedales como imprescindibles para la vida de las aves ${ }^{22}$. Y esas consideraciones

sabio rey don Alonso el nono nuevamente glosadas por el licenciado Gregorio López del Consejo Real de Indias de su Magestad (sic) (1555). Madrid: BOE, 1985, Partida II, Título XX, Ley VII, p. 69.

${ }_{14}$ Un ejemplo entre muchos: «Sin duda que a ella [la agricultura] debe la naturaleza grandes mejoras. A do quiera que se vuelva la vista, se ve hermoseada, y perfeccionada por la mano del hombre. Por todas partes descuajados los bosques, ahuyentadas las fieras, secos los lagos, acanalados los ríos, refrenados los mares, cultivada toda la superficie de la tierra, y llena de alquerías y aldeas, y de bellas y magníficas poblaciones, se ofrecen en admirable espectáculo los monumentos de la industria humana, y los esfuerzos del interés común, para proteger y facilitar el interés individual»; Jovellanos, Gaspar Melchor. Informe de la Sociedad Económica de esta corte al Real y Supremo Consejo de Castilla en el expediente de Ley Agraria. Madrid-Valladolid: Maxtor, 2003, p. 126.

15 Furió, «La domesticación del medio natural», pp. 62-67.

16 Le Goff, Jacques. «El desierto y el bosque en el Occidente medieval». En Le Goff, Jacques. Lo maravilloso y lo cotidiano en el Occidente medieval. Barcelona: Gedisa, 20083, pp. 49-50.

17 Hermon, «Riparia dans l'Empire Romain», p. 8.

18 Isidoro de Sevilla, Etimologías, p. 152.

19 Fumagalli, Vito. Paesaggi della paura. Vita e natura nel Medioevo. Bologna: Il Mulino, 1996, p. 79.

20 "Como el dolor, si con los hospitales/de Valdiquiana entre junio y septiembre, /los males de Maremma y Cerdeña, /en una fosa juntas estuvieran, /tal era aquí; y tal hedor desprendía, /como suele venir de miembros muertos»; Divina Comedia (Infierno, XXXIX), pp. 45-49. El tema ha sido bien estudiado por Marrocchi, Mario. "L'impaludamento della Val di Chiana in epoca medievale». En Malvolti e Pinto (a cura di), Incolti, fiumi e paludi, pp. 73-93.

21 Braudel, Fernand. El Mediterráneo y el mundo mediterráneo en la época de Felipe II. 2 vols. México: FCE, 19932, vol I, p. 84.

22 «Las aves acuáticas prefieren permanecer en el agua y raramente la abandonan. Cuando lo hacen no es en busca de comida o por otra razón que no sea para volar de una masa de agua a otra durante sus migraciones estacionales». Enumera serretas, cormoranes, cisnes y "aquellas aves que Aristóteles en su Historia natural llama pelícanos y los habitantes de Apulia apodan cofani». Incluye aquellas que «visitan masas de agua 
EMILIO MARTÍN GUTIÉRREZ

INTERACCIÓN SOCIEDAD Y MEDIO AMBIENTE. EL ENTORNO DE LA LAGUNA DE LOS TOLLOS

(ANDALUCÍA OCCIDENTAL), SIGLOS XIII AL XV

de carácter teórico también se hallaban en lugares concretos como en los asentamientos altomedievales que rodeaban el marjal en la desembocadura del Segura, donde se conjugaba agricultura, caza, pesca, recolección forestal y aprovechamiento de los humedales ${ }^{23}$; o en Languedoc, donde las lagunas integraban la reserva señorial con abundancia de recursos: pesca, caza, recolección de plantas o pastizales ${ }^{24}$. En la llanura padana la foresta abitata, conocida por el hombre, fue modificada por la economía silvo-pastoril. Atravesada por caminos y senderos, los animales salvajes convivían con el ganado ovino, caprino o de cerda. Había una "popolazione che, per così dire, viveva nell' acqua " $^{25}$. Cambios culturales y diferentes paisajes sociales que «responden a la lógica del sistema social que lo ha creado más allá de las condiciones ecológicas del medio físico» ${ }^{26}$.

Tomando en consideración el estado de la cuestión, que he resumido de forma sucinta, analizo el entorno de la laguna de los Tollos y El Cuervo en el límite de las actuales provincias de Cádiz y Sevilla. Junto a la bibliografía especializada y la documentación de archivo -como los deslindes y pleitos de términos- y el registro arqueológico, el modelo de microhistoria ambiental me parece apropiado ${ }^{27}$. El objetivo es reflexionar en torno a la interacción sociedad y medio ambiente entre los siglos xIII y XV. Este estudio se enmarca dentro de un proyecto en el que profundizaremos en el conocimiento de los humedales en Andalucía Occidental a finales de la Edad Media.

\section{El paisaje de la laguna de los Tollos y su entorno}

El sustantivo tollo-como derivación del hábitat pantanoso de una especie de cazónse utiliza para designar un atolladero y un hoyo «formado en la tierra, del que usan los cazadores para ocultarse a la vista de la caza ${ }^{28}$.

Si se quiere profundizar en su significado hay que acudir a la literatura cinegética. En el Tratado de montería del siglo XV se describe la sierra de Segura con un vocabulario específico acorde al paisaje de ese espacio. Tras nombrar «algunos lugares llanos que son

pero sólo para beber y bañarse», como codornices, perdices, faisanes, avutardas comunes y menores; Federico II de Hohenstaufen. El arte de cetrería. De arte venandi cum avibus. Madrid: Alcotán Cairel Ediciones, 2004, pp. 13-17.

${ }_{23}$ GutiérRez Lloret, Sonia. «Tradiciones culturales y proceso de cambio entre el mundo romano y la sociedad islámica». En Actas del XXIII Congreso Nacional de Arqueologia (Elche 1995). [Elche: Ayuntamiento], 1996, pp. 317-334.

24 Авве́, Jean-Loup. «Técnicas de drenaje y sociedad feudal: las lagunas del Languedoc». En TorRó y Guinot (eds.). Hidráulica agraria y sociedad feudal, pp. 187-206, esp. pp. 187-188 y 190-191.

25 Fumagalli, Paesaggi della paura, pp. 208-209. Sobre la evolución y cambios en este espacio durante el xv: Cazzola, Franco. «Il Po». En Matheus et al., Le calamità ambientali, pp. 215-227.

26 Furió, La domesticación del medio natural, p. 103.

27 Deslinde entre Jerez y Lebrija por Alfonso X en 1274 en González Jiménez, Manuel (ed.). Diplomatario andaluz de Alfonso X. Sevilla: El Monte, 1991, pp. 440-443. AMJF, AHR, Amojonamiento de Jerez y Lebrija de 1434, Cajón 17, n. ${ }^{\circ}$ 9, año 1434, s/f. Informe de 1569 del pleito entre Jerez y Lebrija con la declaración de testigos de los pleitos de 1464, 1503, 1508, 1509, 1510, 1511 y 1552 en AMJF, AHR, Cajón 2, 806, Allegatio ivris pro ciuitate Xeritii contra ciuitatem Hispalensem et eius villam Nebrisensem, s/f. 535-539.

28 Corominas, Joan. Diccionario crítico etimológico castellano e hispánico. Madrid: Gredos, 1983, pp. 
EMILIO MARTÍN GUTIÉRREZ

INTERACCIÓN SOCIEDAD Y MEDIO AMBIENTE. EL ENTORNO DE LA LAGUNA DE LOS TOLLOS

(ANDALUCÍA OCCIDENTAL), SIGLOS XIII AL XV

recojederos de aguas», se precisa que, «si el tal paresçe rezio e debaxo ay agua, llamase tremedal e atolladero» ${ }^{29}$. En la descripción del cazadero de las Roçinas, en Niebla, se advertía que «no se puede correr esta tierra si non en yuierno muy seco, que non sea lluuioso. Et la razón porqué, porque ay muchos tremedales en yuierno lluuioso; et en verano non es de correr, porque es muy seca et muy dolentiosa» ${ }^{30}$.

En la sierra de Segura, en la marisma del Guadalquivir o en las albinas de marisma en Lebrija -que recibían ese nombre por «el color que toma de la sal cuajada la superficie de la tierra que cubría el estero o marisma» ${ }^{31}$ - estas palabras, a las que podrían sumarse otras, ayudan a describir unos paisajes marcados por el agua ${ }^{32}$.

La laguna de los Tollos es un humedal de interior, de tipo estancado, con aguas salinas y en origen de carácter semipermanente, si bien actualmente presenta un régimen hídrico marcadamente estacional asociado al régimen de lluvias. Ubicada en una cota de 55 metros sobre el nivel del mar al suroeste de la depresión del Guadalquivir, tiene una extensión de 83,7 hectáreas ${ }^{33}$. En cambio, su superficie rondaba las 110 hectáreas en los años centrales del siglo XVIII según el Catastro de Ensenada ${ }^{34}$. Quizás esa reducción pudiese estar asociada a los procesos roturadores que afectaron a la dinámica de sus cuencas. Lo que sí está demostrado es que su funcionamiento se vio alterado en el último cuarto del siglo $\mathrm{xx}^{35}$ : entre 1976 y 1998 se vio afectada por una explotación minera que

29 Duque de Almazán (ed.). Tratado de montería del siglo XV. Madrid: [s. n.], 1936, p. 196.

30 Alfonso XI. Libro de la montería, ed. María Isabel Montoya. Granada: Universidad, 1992, pp. 643-644. López Ontiveros, Antonio; Valle Buenestado, Bartolomé y García Verdugo, Francisco R. "Caza y paisaje geográfico en las tierras béticas según el Libro de la Montería». En Andalucía entre Oriente y Occidente (1236-1492). Actas del V Coloquio internacional de Historia Medieval de Andalucía. Córdoba: Diputación Provincial, 1986, pp. 281-307, esp. p. 297.

31 Citado en Tomassetti, José María y Caro Bellido, Antonio, El Cuervo de Sevilla: en el centro de una historia. Primera parte (Prehistoria y Edad Media). El Cuervo: Ayuntamiento, 1999, p. 77.

32 Los tollos del Alamillo, Amarguillo, Asical, Hornix, Huerta, Malvenda o Malduenda, Marmolejo, Montoronja, Paternilla, Pedro Martín, Pedro Rodríguez, Trompeta y Esmenin formaron parte de los bienes de propios de Lebrija durante el primer cuarto del Xvir. El dato en J. Bellido, La patria de Lebrija. Lo cito a través del artículo de García GuZmán, María del Mar. «Aprovechamientos ganaderos en la Tierra de Sevilla: los pozos y tollos de Lebrija a fines de la Edad Media». En Homenaje a don José Bellido Ahumada. Sevilla: Publicaciones de la Muy Ilustre y Real Hermandad de los Santos de Lebrija, 2006, pp. 157-183. Fernández, Manuel F., "La villa de Lebrija a finales del reinado de Felipe III. El padrón de Bula de Santa Cruzada de 1620». Revista de Humanidades, 2009, vol. 16, pp. 59-90, esp. p. 84

33 Se localiza en el límite de las provincias de Cádiz y Sevilla, en el término municipal de Jerez (90\%) y El Cuervo (10\%). Así en la cartografía desde el Mapa Topográfico Nacional de 1918. La identificación entre la ciudadanía de El Cuervo de Sevilla y la laguna de los Tollos o del Tollón es manifiesta. Blenco RodríGuez, Juan y Candón Sánchez, Simón. El Cuervo. Formación y evolución. Cádiz: Serigráfica Andaluza, 2012, pp. 334-339 y 351 .

34 Durante la desamortización de Pascual Madoz se pusieron a la venta las suertes de El Cuervo, Laguna de los Tollos y Dehesa Laguna de los Tollos. Jiménez Blanco, José Ignacio. Privatización y apropiación de tierras municipales en la Baja Andalucía. Jerez: Ayuntamiento, 1996, pp. 275, 277 y 279.

35 En Andalucía, durante el siglo xx, cerca de 120 humedales y casi dos terceras partes de su superficie fueron desapareciendo por la bonificación y los trabajos agrícolas. La política de conservación de Espacios Naturales Protegidos ha salvaguardado 134 humedales entre los que se cuentan lagunas, lagos, tollos, charcas, charcones, marismas, deltas, estuarios, salinas o esteros. Zoido Naranjo, Florencio. "Paisajes de agua". En XII Congreso de Historia Agraria. 13, 14 y 15 de marzo de 2008. Córdoba, 2010, (edición en CD). 
EMILIO MARTÍN GUTIÉRREZ

INTERACCIÓN SOCIEDAD Y MEDIO AMBIENTE. EL ENTORNO DE LA LAGUNA DE LOS TOLLOS

(ANDALUCÍA OCCIDENTAL), SIGLOS XIII AL XV

alteró su funcionamiento hídrico. En la actualidad, la Consejería de Medio Ambiente y Ordenación del Territorio lleva a cabo la restauración de la laguna a través del proyecto LIFE + Los Tollos, cofinanciado por la Unión Europea, cuyo objetivo general es solucionar la problemática asociada a la degradación del suelo ${ }^{36}$.

Desde la geología, la geografía o la ecología los humedales andaluces han sido abordados destacando una primera aproximación de Juan Dantín en $1940^{37}$ y la catalogación posterior de Pardo $^{38}$. Desde la Historia y en las tierras gaditanas hay investigaciones muy valiosas como el estudio multidisciplinar de la laguna del Gallo en el término de El Puerto de Santa María o el aprovechamiento de los humedales en la Bética romana ${ }^{39}$.

La aproximación al objeto de estudio requiere la comprensión de cuatro aspectos importantes: los cambios en el paisaje en el Bajo Guadalquivir, el funcionamiento de la laguna de los Tollos, las características edafológicas y la incidencia de la sierra de Gibalbín. Como veremos a continuación, en cada una de esas líneas el agua adquiere una relevancia especial aportando una clave interpretativa para un mejor conocimiento de la interacción de la sociedad bajomedieval con el medio ambiente.

\subsection{Los cambios en la fisonomía del territorio: de un espacio lacustre a uno marismeño}

El paisaje no es estático sino que cambia continuamente a lo largo del tiempo geológico e histórico. El Bajo Guadalquivir fue un espacio lacustre denominado Lacus Ligustinus $^{40}$. Si en el Pleistoceno el estuario del Guadalquivir estuvo abierto al mar

36 Tras la adquisición e incorporación de la laguna de los Tollos como propiedad pública, se puso en marcha un proceso de participación capitaneado por un equipo interdisciplinar, cuyo resultado fue la propuesta técnica presentada a la convocatoria 2009 del Programa LIFE+ de la Unión Europea. El proyecto consta de una restauración minera en la cubeta transformada y una restauración ambiental en el resto de la cuenca. Proyecto para la restauración integral de la cubeta endorreica de los Tollos (El Cuervo y Jerez de la Frontera, Sevilla y Cádiz respectivamente). CAPMA (CMAOT) 2009.

37 DAntín, Juan. «La aridez y el endorreísmo en España. El endorreísmo bético». Estudios Geográficos, 1940, vol. 1, pp. 75-117, esp. pp. 105-108. DueÑAs, Manuel Ángel y Recio, José Manuel. Bases ecológicas para la restauración de los humedales de la Janda (Cádiz, España). Córdoba: Universidad, 2000. Ortiz Botella, Francisco Javier y Molina VázQuez, Jesús. «Aproximación ambiental a las lagunas endorreicas protegidas de la provincia de Sevilla (España)». Revista de Estudios Andaluces, 1995, vol. 21, pp. 145-164. Colón, Manuel y Díaz, Fernando. Guías naturalistas de la provincia de Cádiz. Las Campiñas. Cádiz: Diputación, 1990, pp. 230-232.

38 Pardo, Luis. Catálogo de los lagos de España. Madrid: Instituto Forestal de Investigaciones y Experiencias, 1948.

39 Ruiz Gil, José Antonio y López Amador, Juan José (coords.). Formaciones sociales agropecuarias en la Bahía de Cádiz. 5000 años de adaptación ecológica en la Laguna del Gallo. El Puerto de Santa María. Cádiz: Arqueodesarrollo Gaditano, 2001. Lagóstena BARrios, Lázaro. «Riparia: conceptualización histórica, función territorial y aprovechamiento de los humedales en la Bética romana». En Colloque "Nouvelles approches de l'ingénierie hydraulique romaine». Actualité de la recherche en France et en Espagne. Toulouse 15-16 février 2013 (en prensa).

40 «Ocupaba una superficie estimada de $1.600 \mathrm{~km}^{2}$, un perímetro de $690 \mathrm{~km}$, una longitud NE-SW de $68 \mathrm{~km}$ y una anchura máxima NW-SE de $34 \mathrm{~km}$. A sus orillas se fueron estableciendo poblaciones que se convertirían en las futuras comunidades cívicas de Hasta Regia, Conobaria, Nabrissa Veneria, Orippo, Caura 
EMILIO MARTÍN GUTIÉRREZ

INTERACCIÓN SOCIEDAD Y MEDIO AMBIENTE. EL ENTORNO DE LA LAGUNA DE LOS TOLLOS

(ANDALUCÍA OCCIDENTAL), SIGLOS XIII AL XV

coincidiendo las mareas y el caudal del río, durante el Holoceno se fue reduciendo debido a los depósitos de arenas, gravas y cantos rodados. El aumento del componente oceánico respecto al fluvial fue generando la formación de la contraflecha de La Algaida ${ }^{41}$.

Conforme la línea de costa fue retirándose la cubeta de los Tollos se fue rellenando de limos, margas y arcillas. Como se observa en el Mapa 1, que reproduce el término de Jerez a finales de la Edad Media, en los ángulos noroeste y nordeste del término jerezano se hallan las marismas de los antiguos estuarios marinos del Guadalquivir y Guadalete ${ }^{42}$. Durante los siglos medievales aún era frecuente la navegabilidad en algunos cańos en Alventos y Casarejo próximos a Asta ${ }^{43}$. Quizás por ello al-Idrisi describiese «la provincia llamada del Lago, que se extiende desde los bordes del Océano hasta los del Mediterráneo» o Antonio de Nebrija reflexionase sobre los cambios en «aquella madre del río que bañaba Lebrija y Asta»:

y Olontigi»; Lagóstena Barrios, Lázaro. "La percepción de la ribera en la costa atlántica de la provincia Hispania Ulterior Baetica. El Lacus Ligustinus». En Savoirs et pratiques de gestion intégrée des bords de l'eau. Sudbury, 2012 (en prensa). Gavala y Laborde, Juan. "Memoria explicativa de la Hoja de El Asperillo». Madrid: Instituto Geológico y Minero de Espańa, 1936. Arteaga Matute, Oswaldo y roos, Ana María. «El proyecto geoarqueológico de las marismas del Guadalquivir. Perspectivas arqueológicas de la campaña de 1992». Anuario Arqueológico de Andalucía, 1995, vol. 92, n. ${ }^{\circ}$ II, pp. 329-339. Caro Bellido, Antonio y Tomassetti Guerra, José María. Antonio de Nebrija y la Bética. Sobre arqueología y paleogeografia del Bajo Guadalquivir. [Cádiz]: Servicio de Publicaciones de la Universidad de Cádiz y Hermandad de los Santos de Lebrija, 1997.

41 Bocanegra Barba, José Antonio. «Hidrología y vegetación potencial del entorno de los emplazamientos históricos de Asido, Carteia, Ocuri, Hasta, Gades y Baelo». En Lagóstena Barrios, Lázaro y Zuleta Alejandro, Francisco (coords.). La captación, los usos y la administración del agua en la Baetica: estudios sobre el abastecimiento hidrico en comunidades cívicas del Conventus Gaditanus. Cádiz: Universidad, 2009, pp. 61-85, esp. p. 73. La actual Marisma del Guadalquivir con $2.000 \mathrm{~km}^{2}$ es una zona de carácter fluviomarino, con suelos compactos, escasa aireación y permeabilidad, drenaje deficiente y altos niveles de salinidad. Condiciones que explican su tradicional aprovechamiento ganadero extensivo y estacional. Una orientación puesta de relieve por cronistas y viajeros y que ha recibido la atención de los historiadores. En cualquier caso, el actual paisaje marismeño también es el resultado de la transformación iniciada en la segunda década del siglo xx. Florido Trujillo, Gema. Hábitat rural y gran explotación en la Depresión del Guadalquivir. Sevilla: Junta de Andalucía, 1996, pp. 53-54. Herrera, Francisco et ál. «El marco agrario. Historia y paisaje». En Cortijos, haciendas y lagares. Arquitectura de las grandes explotaciones agrarias de Andalucía. Provincia de Sevilla. 2 vols. Sevilla: Consejería de Vivienda y Ordenación del Territorio, 2009, vol I, pp. 39-93, esp. pp. 87-93. Bazzana, André y Bedia, Juana. Saltés. Un asentamiento islámico en las marismas del Odiel (siglos IX-XIII). Sevilla: Casa de Velázquez-Diputación Provincial de Huelva, 2009, p. 67.

42 González Rodríguez, Rosalía y Ruiz Mata, Diego, «Prehistoria e Historia Antigua de Jerez». En Caro Cancela, Diego (coord.). Historia de Jerez de la Frontera. De los orígenes a la época medieval. Cádiz: Diputación, 1999, vol I, pp. 19-188, esp. pp. 20-32. Por ejemplo, el arroyo del Blanquillo, como apuntaba Juan Dantín, fluye a veces por la cañada de Albadalejo y habría «sido en tiempos, efectivamente, algún brazo, hoy muerto y desecado del Guadalquivir»; DAnTín, La aridez y el endorreísmo, pp. 105-107.

43 Martín Gutiérrez, Emilio. "Análisis de la toponimia y aplicación al estudio del poblamiento. El alfoz de Jerez de la Frontera durante la Baja Edad Media». Historia. Instituciones. Documentos, 2003, vol. 30, pp. 257-300, esp. pp. 259 y 261. En Casarejo-5 se ha detectado una alquería almohade en lo que fue un puerto natural y materiales cristianos de los siglos XV y xvi. BARrionuevo Contreras, Francisco; Aguilar Moya, Laureano y González Rodríguez, Rosalía. «Prospección arqueológica superficial del extremo noroccidental de la provincia de Cádiz. Campańa 1994». Anuario Arqueológico de Andalucía/1994 II. Actividades Sistemáticas, Sevilla, II, (1999), pp. 33-36, esp. p. 34. 
EMILIO MARTÍN GUTIÉRREZ

2 INTERACCIÓN SOCIEDAD Y MEDIO AMBIENTE. EL ENTORNO DE LA LAGUNA DE LOS TOLLOS

(ANDALUCÍA OCCIDENTAL), SIGLOS XIII AL XV

Por fin desemboca [el Guadalquivir] en el mar por una sola boca junto a la población llamada por los antiguos Templo de Lucifer. En otro tiempo, este río tuvo dos desembocaduras [...]. Según Estrabón, Ptolomeo, Mela y Plinio y todos los demás cosmógrafos, Lebrija y la colonia de Asta estaban situadas dentro del estuario del Betis. ¿Qué pudo pasar para que ahora disten del río no menos de ocho mil pasos? Sin duda que aquella madre del río que bañaba Lebrija y Asta se cerró con el limo, aunque, a pesar de ello, se ven hoy en día esteros y canales de conducción fabricados, como dice Estrabón, para transportar en esquifes y chalupas los productos de la tierra desde los campos a las ciudades vecinas ${ }^{44}$.

Las marismas del norte del término de Jerez aún tuvieron una presencia en el paisaje hasta tiempos relativamente recientes. En 1818 fueron registradas las del Rincón -Bujón, Rajaldabas y Tabajete-, linderas con Trebujena, con una superficie de 300 hectáreas; las de Casablanca, junto a la estación de El Cuervo, con 175,375 hectáreas; las de Los Prados de Anguillas, en la linde con Lebrija, con 29,5 hectáreas; o las de Casarejo y Mesa de Asta con 245,125 hectáreas ${ }^{45}$. Aunque en aquel momento fueron calificadas como improductivas, en las siguientes páginas prestaremos atención a sus aprovechamientos por las comunidades campesinas durante los siglos bajomedievales.

\subsection{El funcionamiento del humedal: cursos fluviales y acuiferos}

Desde una perspectiva ecológica un humedal es un ecosistema de carácter acuático que genera una anomalía hídrica positiva en un entorno $\operatorname{seco}^{46}$. La climatología adquiere relevancia ya que el nivel de precipitaciones y evapotranspiración de las aguas desde el acuífero son claves para su funcionamiento, determinando en última instancia la relación de equilibrio entre los humedales y los acuíferos asociados. La escasa pluviometría y alta insolación provocan que muchos humedales andaluces estén secos durante los meses estivos $^{47}$.

La cuenca de recepción de la laguna de los Tollos es relativamente pequeña con 670 hectáreas. Mientras que los arroyos Fuente de la Salud, Pellejero, Molineta o

44 El texto de Antonio de Nebrija en Tomassetti y Caro, El Cuervo de Sevilla, p. 80.

45 Lozano Salado, Lola. La tierra es nuestra. Retrato del agro jerezano en la crisis del Antiguo Régimen. Cádiz: Universidad, 2002, p. 91.

46 Plan Andaluz de Humedales. CAPMA (CMAOT).

47 Un planteamiento interdisciplinar con bibliografía adecuada en Hermon, Ella. «Perspectives interdisciplinaires sur l'histoire des interactions climat-société-environnement: leçons du passé et leur pertinence pour le présent». En Hermon (dir.), Société et climats dans l'Empire Romain, pp. 19-50. Reflexiones interesantes en Delort e Walter, Storia dell'ambiente, pp. 149-156. Para la época medieval peninsular: Segura Graíño, Cristina. «Les recherches sur le climat dans la Couronne de Castille au Moyen Âge». En Clé́ment (dir.), Histoire et nature, pp. 147-160. Riera, Santiago et ál. "Variabilité climatique, occupation du sol et paysage en Espagne de l'Âge du Fer à l'époque médiévale: intégration des données paléoenvironnementales et de l'archéologie du paysage». En Hermon (dir.), Société et climats dans l'Empire Romain, pp. 251-280. El período entre 1300 y 1550 -fase intermedia entre el Período Cálido Medieval y la Pequeña Edad de Hielo- se viene caracterizando por un aumento del frío y las precipitaciones. A pesar de su subjetividad, las crónicas abordan estas cuestiones. Collantes de Terán, Antonio. Sevilla en la Baja Edad Media. La ciudad y sus hombres. Sevilla: Ayuntamiento, 19842, pp. 431-440. 
EMILIO MARTÍN GUTIÉRREZ

INTERACCIÓN SOCIEDAD Y MEDIO AMBIENTE. EL ENTORNO DE LA LAGUNA DE LOS TOLLOS

(ANDALUCÍA OCCIDENTAL), SIGLOS XIII AL XV

Prados discurren entre las Peńas del Cuervo y la marisma de Casablanca, los temporales del Alamillo y Salado descienden desde el piedemonte de la sierra de Gibalbín ${ }^{48}$. Su regularidad o irregularidad condicionaba la vida de las comunidades campesinas. Un ejemplo entre muchos: en los años treinta del siglo xvi el lebrijano Luis Marín reconocía que durante el invierno y «en tienpo que ay yerva verde e corren los arroyos, son los pastos e aguas comunes». Razón por la cual «todos se aprovechan de la yerva e agua». La situación era diferente en el verano, ya que "en tiempo de agostadero en que se secan las aguas de los dichos arroyos, cada vno se va a su término a agostar sus ganados» ${ }^{49}$.

Una de las características de la laguna de los Tollos es su salinidad debido a la composición de los terrenos por donde discurren los arroyos vertientes de su cuenca, como también a los materiales del acuífero asociado de formación cuaternaria. Durante las primeras décadas del siglo Xvi algunos testigos corroboraron la salinidad de los arroyos -muy frecuentes en estos espacios- y de forma muy gráfica relataban «que gustaron el agua y que estaua salada». Y también describían unas salinas junto al molino del Cubo que «estauan medio tiro de ballesta deste dicho mojón [el molino del Cubo] como paresce en el dicho memorial». Y precisaban: se hallaban «junto a la dicha laguna de Toyos y en el camino que va de Xerez a las Cabeças [de San Juan] $»^{50}$.

Los cursos fluviales favorecían las comunicaciones. En la crónica de Alfonso XI se incluye el itinerario desde Sevilla hacia el Estrecho de Gibraltar citando el arroyo Salado y los ríos Guadalete, Barbate y Almodóvar ${ }^{51}$. Pero también los ríos entorpecían el paso ${ }^{52}$. En los alrededores de Jerez una red de arroyos, tributarios del Guadalete, circundaba la ciudad dificultando el movimiento de personas y mercancías, lo que exigía la construcción de puentes y la mejora de los accesos ${ }^{53}$.

48 AMJF, AHR, Allegatio ivris, s/f.

49 ARCG, Pleito Utrera-Lebrija, s/f.

so AMJF, Allegatio ivris, s/f.

51 «El día que partieron de las Cabeças de San Joan fueron a posar a las Cueuas de los Toyos. E otro día fueron a posar çerca de vn arroyo que dizen el Salado, que es en par de Xerez a vna legua dende, e non fueron a la villa de Xerez por los guardar del daño que los de la hueste les ficieran sy por ay fueran en las huertas e en las vińas y en los olivares. E otro día partieron ende los reyes, e fueron a posar allende Guadalete»; $I^{o}$ tomo de la edición crítica de la Gran crónica de Alfonso XI, ed. Diego Catalán. Madrid: Gredos, 1977. Fuentes cronísticas de la Historia de España, 4, p. 390. López Fernández, Manuel. «De Laguna de los Tollos al Campo de Gibraltar: la vía gaditana más frecuentada por Alfonso XI de Castilla». Eúphoros, 2004, vol. 7, pp. 35-48, esp. p. 37.

52 En otra ocasión se describía la capacidad del monarca para construir puentes, embarcaciones o arreglar caminos. «Et porque él entendía que le convenía morar el invierno que venía en la cerca de aquella ciubdat, mandó facer en el río de Barvate cerca de Vejer una puente et otra puente en un arroyo cerca de Xerez por do pasaba el camino: et mandó facer barcos en el río Guadalete, por do pasasen los omes et las viandas que levasen por tierra en el invierno: et mandó faser otras puentes en logares convenibles et endereszar los caminos en muchos logares desde Xerez fasta Algeciras»; "Crónica de don Alfonso el Onceno». En Colección de las crónicas y memorias de los reyes de Castilla. Madrid: Antonio de Sancha, 1787, vol. VII, pp. 493-494.

53 Abellán Pérez, Juan. «Construcción y reparación de estructuras viales. Jerez de la Frontera en el siglo XV». En Abellán Pérez, Juan. La ciudad de Jerez de la Frontera y el Reino de Granada. Helsinki: Academia Scientiarum Fennica, 2006, pp. 43-58. 
EMILIO MARTÍN GUTIÉRREZ

\subsection{Las características edafológicas}

Los tratados de agronomía son una fuente para comprender la interacción de la sociedad con el medio ambiente. Gabriel Alonso de Herrera enumeraba las señales que permiten diferenciar «la malicia y bondad de la tierra» y aportaba soluciones para corregir siempre que fuese posible los "defectos de algunas tierras» ${ }^{54}$.

La laguna de los Tollos se asienta sobre materiales de la zona Subbética y depósitos detríticos de la depresión del Guadalquivir. Entre el humedal y la marisma de El Cuervo hay una franja de terreno de arcillas margosas azuladas del mioceno superior, margas blancas, arenas pliocenas y materiales de depósito lagunar compuestos por margas, limos y arcillas. Si su elevado componente salino las hace poco apropiadas para la agricultura y muy útiles para la ganadería, allende la marisma de El Cuervo los suelos de bujeos y albarizas son óptimos para el cereal y el vińedo ${ }^{55}$.

En el sector hispalense la vegetación potencial está marcada fundamentalmente por encinares ${ }^{56}$. Los cazaderos de la Xara de Utrera, monte de la Xarilla de Mosquete en las Cabezas de San Juan, la Xara de Viñuelas en Alcalá de Guadaíra y la Porquera de Espera, no muy alejados de la laguna de los Tollos, recrean el ambiente de esos espacios $^{57}$. En su significado biogeográfico el monte existía «casi exclusivamente a base de jarales» con una vegetación de matorral, «espinar» o «espinarejo», y otra de ribera, «alamedas», «cañaveralejo», o "cañaverales del Guadalete». Solo se usaba el topónimo encinar para aludir a una vegetación arbórea espontánea ${ }^{58}$. En las primeras décadas del XVI había "muchas matas de lantiscos y retamas y toruiscos» en las cercanías de Peña Rubia $^{59}$ y aún en 1621 -al elaborarse un informe que dividía el término jerezano en cuatro grandes zonas: Rincón, Palomares, Ribera y Realengo- se afirmaba que había

54 Como corolario reconocía que no había «remedio para enmendar las calidades de los terruños como aprovecharse dellos según que requiere su naturaleza, porque toda tierra es hábil para fructificar en toda manera de fruto, como muy bien dice Virgilio, y por eso es bueno apropiar a cada tierra lo que bien y propiamente le pertenesce y puede llevar»; Herrera, Obra de agricultura, pp. 12-14.

55 Ramos Muñoz, José et ál. "Tecnología lítica de las edades del Cobre y Bronce en la marisma del Cuervo (Jerez de la Frontera, Cádiz)». SPAL, 1992, vol. 1, pp. 151-177, esp. p. 154.

56 Encinar serie SmQr: «encinar que, en su primera etapa de sustitución, alcanza a ser un coscojal/ lentiscar, acompañado de escobonales/retamares, espartales, romerales/aulagares/tomillares, pastizales $\mathrm{u}$ otras series de comunidades en función de la biogeografía». Encinar serie PcQr: «encinar que se degrada a coscojal. En las zonas más soleadas aparecen orlas de retamares, en suelos profundos, de poca pendiente y secos; espartales en los suelos con acusada xericidad; o, en los degradados y pobres, tomillares y romerales. En suelos muy erosionados, y con afloramientos rocosos, se sitúa el pastizal/tomillar. En las zonas lluviosas el encinar se enriquece con quejigos, en parecida transición que las comunidades degradadas de los acerales/ quejigales». Puntualmente representado el encinar serie McQs: «alcornocal que, en las zonas umbrías y lluviosas, se enriquece con quejigos. La primera etapa de sustitución la constituye un madrońal, aunque en las zonas con acusada sequía lo hace un coscojal-espinar. En los claros del alcornocal pastoreado aparece un retamal; y, en las zonas incendiadas, un jaral»; BocANEGra BARBA, «Hidrología y vegetación potencial», pp. 81-83.

57 Alfonso XI, Libro de la montería, pp. 641 y 644.

58 López Ontiveros, Valle Buenestado y García Verdugo, Caza y paisaje, p. 296.

59 AMJF, Allegatio ivris, s/f. 
EMILIO MARTÍN GUTIÉRREZ

INTERACCIÓN SOCIEDAD Y MEDIO AMBIENTE. EL ENTORNO DE LA LAGUNA DE LOS TOLLOS

(ANDALUCÍA OCCIDENTAL), SIGLOS XIII AL XV

«algunos pedaços de palmares» en los Palomares «por cuya causa -se esgrimía- no hera toda la tierra tan igual» como en otras de la campiña ${ }^{60}$.

\subsection{La sierra de Gibalbin}

La sierra de Gibalbín con 410 metros sobre el nivel del mar se yergue en el entorno de los Llanos de Caulina como puede apreciarse en el Mapa 3. Está situada en un lugar estratégico -en 1434 era "departimiento de los términos de las aldeas de Gratituna y Carrizal» ${ }^{61}$ - y con amplios recursos naturales. Si su silueta domina el entorno, siendo percibida como «la más principal demostración de todo el término ${ }^{62}$, desde su cumbre se obtiene una visión que no dudaría en calificar como espectacular ${ }^{63}$. A su presencia en un espacio horizontal se le podría aplicar el término iconema con el que el geógrafo Eugenio Turri engloba aquellos paisajes recreados a través de una imagen ${ }^{64}$.

El significado del topónimo Gibalbín -Yabal bir- alude a Monte del Pozo ${ }^{65}$. En el siglo XIII el geógrafo Yaqut citaba el iqlim al-Manara en las proximidades de Sidonia. Su significado - la Torre- la relaciona con un puesto de vigilancia y comunicación proponiéndose su localización en Gibalbín ${ }^{66}$. En ese espacio los benimerines asaltaron una torre en 1285 que aún se mantenía en pie a principios del $\mathrm{XIV}^{67}$. En el actual cortijo de La Mazmorra hay importantes restos arquitectónicos: paños de murallas y muros, bóvedas, cisternas o fuentes de mampostería identificados con un despoblado de nombre islámico ${ }^{68}$.

La comprobación de un poblamiento prealmohade en Asta y Jerez, ha reabierto la posibilidad de reconsiderar el asentamiento en Ceret y su posterior traslado de la sierra al valle al actual Jerez ${ }^{69}$. En cualquier caso y a pesar de la continuidad del

60 El sector de los Palomares se extendía desde Jerez «y el dicho camino de Sevilla a la parte la vuelta del término de Sevilla y Espera y Arcos hasta el dicho río». Era una zona con abundantes tierras «de labor y heredades, viñas y olibares, guertas y arboledas y de la misma suerte hera todo seńoreado y el pasto y labor de sus dueńos. Tenían algunos pedaços de palmares»; Martín Gutiérrez, La organización del paisaje, pp. 25 y $37-39$.

${ }_{61}$ AMJF, AHR, Amojonamiento Jerez-Lebrija, ańo 1434, s/f.

62 AMJF, Allegatio ivris, s/f.

63 La conexión de la sierra de Gibalbín con las atalayas de la campiña jerezana en SÁnchez SAUS, Rafael y Martín GutiÉrrez, Emilio. «Ordenanzas jerezanas del siglo xv sobre la milicia concejil y la Frontera de Granada». Historia. Instituciones. Documentos, 2001, vol. 28, pp. 377-390.

64 AMJF, AHR, Amojonamiento Jerez-Lebrija, año 1434, s/f.

65 Martín Gutiérrez, «Análisis de la toponimia», p. 267. Bustamante Costa, Joaquín. "Toponimia árabe del cuadrante sudoccidental de la provincia de Cádiz». Janda. Anuario de Estudios Vejeriegos, 1997, vol. 3, pp. 27-42, esp. p. 31 .

66 Abellán Pérez, Juan. Poblamiento y administración provincial en al-Andalus. La cora de Sidonia. Málaga: Sarriá, 2004, p. 28.

67 Martín Gutiérrez, «Análisis de la toponimia», pp. 267-268.

68 Tomassetti y Caro, El Cuervo de Sevilla, pp. 172-174. González Rodríguez y Ruiz Mata, «Prehistoria», pp. 145-147.

69 Abellán Pérez, Poblamiento, pp. 51-53. 


\section{INTERACCIÓN SOCIEDAD Y MEDIO AMBIENTE. EL ENTORNO DE LA LAGUNA DE LOS TOLLOS (ANDALUCÍA OCCIDENTAL), SIGLOS XIII AL XV}

poblamiento "Gibalbín es un yacimiento sobre el que se ha escrito mucho más que investigado» ${ }^{70}$.

Además de la sierra de Gibalbín, cerros, oteros, cabezos y lomos fueron enumerados de forma meticulosa en los sucesivos amojonamientos entre Jerez y Lebrija ${ }^{71}$. Un elenco que se enriquece con las declaraciones de los testigos que acudieron a los pleitos. El cerro del Donato con sus labrados; el puntal de Rascadero desde donde se divisaba "Xarana, el donadío y casas de Monesterejo y la fortaleza de Trebuxena»; el lomo del Gamo o Jara con su vegetación y fauna; las cuevas de los Tollos percibidas «como vnas de las más notables y permanentes señales que [hay] en todo aquel campo»; o Peñas Rubias o Peńas de Ballesteros - «muy altas y muy sumptuosas como grandes casas»cercanas al cortijo del $\mathrm{Cubo}^{72}$.

\section{LA INTERACCIÓN SOCIEDAD Y MEDIO AMBIENTE: SIGLOS XIII AL XV}

En su estudio sobre el Mediterráneo, Peregrine Horden y Nicholas Purcell sostienen que los humedales tenían un marcado carácter local y formaban parte de los recursos ambientales distribuidos en microrregiones diferentes ${ }^{73}$. El entorno de la laguna de los Tollos fue una zona con un poblamiento secular donde el agua y la marisma tuvieron una incidencia en la vida de las comunidades campesinas ${ }^{74}$.

La problemática que analizamos en este apartado nos conduce a la evolución del poblamiento rural y al aprovechamiento de los recursos del entorno. Como veremos a continuación, las marismas y los humedales adquieren un protagonismo significativo que se traduce en el desarrollo de las actividades pecuarias. Frente a esa realidad también tenemos presente las transformaciones que de forma paulatina fueron cambiando el paisaje con la introducción de cultivos en los alrededores de El Cuervo y en la laguna de los Tollos. Junto al camino real, como puede apreciarse en el Mapa 3, que unía Sevilla y Jerez, había senderos, carriles o cañadas -como la Real, Lebrija, Casinas, Gibalbín o Romanina- que entrelazaban las poblaciones y propiedades.

En definitiva, pudiera pensarse que la interacción sociedad-medio ambiente debe ser enfocada bajo la única perspectiva del impacto antrópico cuya manifestación más evidente fue la puesta en cultivo de tierras. Este planteamiento deja sin explicar otras relaciones de «tipo co-evolutivo, interattivo a lunga durata: tale rapporto è un fenomeno storico, in continuo sviluppo nel corso del tempo» ${ }^{75}$.

70 Mata Almonte, Esperanza. «Precedentes de los aprovechamientos hídricos en la Antigüedad gaditana. El mundo turdetano». En Lagóstena Barrios y Zuleta Alejandro (coords.), La captación, los usos y la administración del agua en la Baetica, pp. 87-114, esp. p. 104.

71 González Jiménez, Diplomatario andaluz, pp. 440-443. AMJF, AHR, Amojonamiento Jerez y Lebrija, año 1434, s/f. AMJF, Allegatio ivris, s/f.

72 AMJF, Allegatio ivris, s/f.

73 Horden and Purcell, The corrupting sea, pp. 186-190.

74 Tomassetti, y Caro, El Cuervo de Sevilla, pp. 164-176.

75 Tosco, Il paesaggio storico, p. 138. 
EMILIO MARTÍN GUTIÉRREZ

INTERACCIÓN SOCIEDAD Y MEDIO AMBIENTE. EL ENTORNO DE LA LAGUNA DE LOS TOLLOS

(ANDALUCÍA OCCIDENTAL), SIGLOS XIII AL XV

Mapa 1.- Término de Jerez de la Frontera.

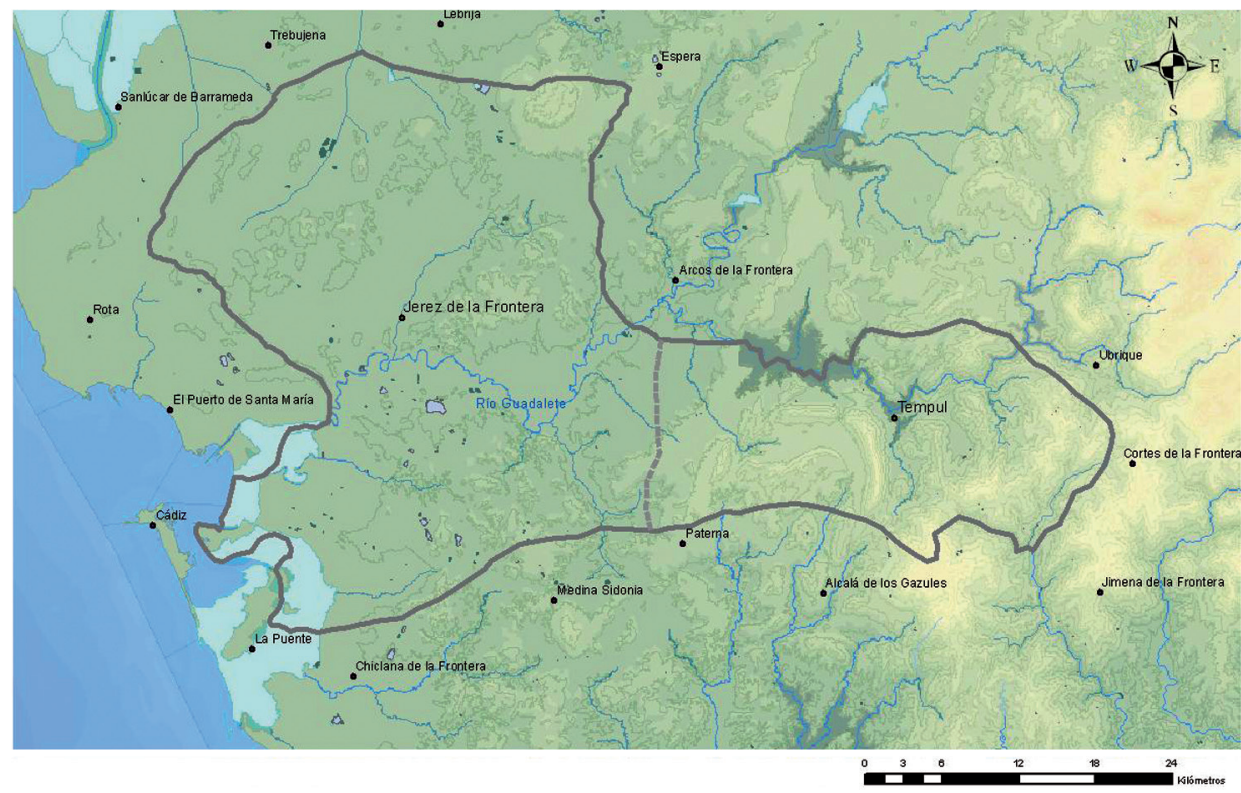

(c) Seminario Agustín de Horozco de estudios económicos de Historia Antigua y Medieval <http://agustindehorozco.uca.es/>.

\subsection{El poblamiento rural en el entorno de la laguna de los Tollos}

Tras la conquista castellana se iniciaba la organización del territorio. La fracasada revuelta mudéjar de 1264 tuvo como consecuencia su expulsión y el abandono de sus bienes. Muchas de sus tierras e infraestructuras rurales no llegaron a ser reutilizadas, proliferando los despoblados. Una situación que comenzó a cambiar con las repoblaciones señoriales y concejiles de finales del XIII y del XIV $^{76}$. No debemos pensar tanto en abandonos masivos de tierras como en una reordenación del poblamiento.

La sensación colectiva de inseguridad asociada a la Frontera, muy presente en algunas zonas de Andalucía entre finales del XIII y el XIv, tuvo una incidencia en la formación de la estructura de la propiedad y, como consecuencia, en la gestación de

76 González Jiménez, Manuel. En torno a los orígenes de Andalucía. La repoblación del siglo XIII. Sevilla: Universidad, 1988. ÍDem. La repoblación de la zona de Sevilla durante el siglo XIV. Sevilla: Universidad, 1993, p. 85. Collantes de Terán, Antonio. «Le latifundium sévillan aux xive et xve siècles. Ébauche d'une problématique». Mélanges de la Casa de Velázquez, 1976, vol. XII, pp. 101-125. García Fernández, Manuel. «Nuevos datos sobre la repoblación del sector sur de la Campiña sevillana durante el siglo XIV». En García Fernández, Manuel. La Campiña Sevillana y la frontera de Granada (siglos XIII-XV). Estudios sobre poblaciones de la Banda Morisca. Sevilla: Universidad, 2005, pp. 31-48. 


\section{INTERACCIÓN SOCIEDAD Y MEDIO AMBIENTE. EL ENTORNO DE LA LAGUNA DE LOS TOLLOS \\ (ANDALUCÍA OCCIDENTAL), SIGLOS XIII AL XV}

los diferentes paisajes ${ }^{77}$. A partir de los años treinta del xiv la Frontera se fue alejando paulatinamente de la campińa jerezana y, por ende, del entorno de la laguna de los Tollos. En 1333 la ciudad de Jerez recibía de Alfonso XI el castillo y término de Tempul, ampliando considerablemente su alfoz más allá de la laguna de Medina hacia la sierra. En el Mapa 2 se presenta el término adjudicado a Jerez de la Frontera con los núcleos rurales repartidos en 1269. En el margen inferior derecho se reproduce el término completo tras la cesión de Tempul ${ }^{78}$.

En 1274 se fijaba la linde entre Jerez, Lebrija y Arcos que discurría entre los «Cinco Árboles» en la «ribera del Guadalquiuir» y Carrizal «ó se parten los términos», incluyendo algunas alquerías $^{79}$. En el Mapa 3 se han georreferenciado los topónimos del entorno de la laguna de los Tollos, incluyendo las alquerías vinculadas a Jerez y Lebrija así como la linde que separaba ambos términos. De especial importancia son los humedales y marismas y las vías de comunicación que unían a Jerez y Sevilla. En el margen inferior derecho se reproduce el humedal a partir de la fotografía aérea de 1956-1957.

Quintana Talhaza (Lebrija). Ubicada entre el otero de Almotán y el cerro del Algoryta, quizás el actual cerro de Santa Catalina. En 1274 el aprovechamiento de la marisma - «en tal manera que se siruan de la marisma los vnos y los otros»- era valorado. En el siglo xv el cortijo de Quincena era propiedad de Juan de Torres y Catalina Ponce de León, mujer del veinticuatro sevillano Pedro Ortiz de Sandoval. Durante la construcción del tramo ferroviario Lebrija-El Cuervo en la línea de Alta Velocidad Sevilla-Cádiz, se han efectuado prospecciones superficiales detectándose cinco áreas con materiales arqueológicos: al oeste de la Casa del Pozo Viejo (Lebrija), en la loma al sur de la Casa del Pozo Viejo (Lebrija), en el cortijo Abajo-Quincena (Lebrija), en la estación de El Cuervo (Jerez) y al sur de la carretera N-IV (Jerez). El más importante es el cortijo de Abajo-Quincena, un yacimiento entre 45 y 50 hectáreas. Los restos en superficie abarcan un amplio período con poblamiento prehistórico, protohistórico, romano y medieval ${ }^{80}$.

Xarana (Jerez). Situada en una cabezuela al pie de la sierra de Alquencina en la «carrera que va de Xerez a Milana». En la campańa arqueológica de 1991 se detectaron restos de una alquería en los cerros de Cápita y Mojón Blanco. Esta alquería fue nombrada

77 Borrero Fernández, Mercedes. La organización del trabajo. De la explotación de la tierra a las relaciones laborales en el campo andaluz (siglos XIII-XVI). Sevilla: Universidad, 2003, pp. 29-67.

78 Martín GutiérRez, Emilio. La identidad rural de Jerez de la Frontera. Territorio y poblamiento durante la Baja Edad Media. Cádiz: Universidad, 2003, pp. 71-73; e ÍDEM, La organización del paisaje, pp. 107-113.

79 En el amojonamiento de 1274 los «cinco árboles» se ubicaban en el lugar de Alistar. En el de 1434 se situaban en el Toconal al pie del Cerro Gordo que quizás se corresponda con el actual cerro de los Toconales. En el pleito de 1569 se localizaban en la Isla Mayor aunque «por auer el dicho río, que es muy caudaloso, rompido y quedado los dichos árboles en la Ysla Mayor, [reconocía que allí] se dividían los términos [entre Jerez y Lebrija] desde los Cinco Árboles que están en la Isla Mayor»; GonZález Jiménez, Diplomatario andaluz, pp. 440-443. AMJF, AHR, Amojonamiento Jerez-Lebrija, año 1434, s/f. AMJF, Allegatio ivris, s/f.

80 González Jiménez, Diplomatario andaluz, pp. 440-443. Sánchez Saus, Rafael. Linajes medievales de Jerez de la Frontera. 2 vols. Sevilla: Guadalquivir, 1996, vol. I, pp. 307 y 308. Sánchez-Capilla Arroyo, María Luz. «Prospección arqueológica en la línea de Alta Velocidad Sevilla-Cádiz. Tramo: Utrera-Aeropuerto Jerez de la Frontera. Subtramo Lebrija-El Cuervo». Anuario Arqueológico de Andalucía, 2004/I, Sevilla, 2009, pp. 3751-3758. 
EMILIO MARTÍN GUTIÉRREZ

INTERACCIÓN SOCIEDAD Y MEDIO AMBIENTE. EL ENTORNO DE LA LAGUNA DE LOS TOLLOS

(ANDALUCÍA OCCIDENTAL), SIGLOS XIII AL XV

por el geógrafo árabe Ibn Sa’̄d en el siglo XIII ${ }^{81}$. En 1274 la marisma quedaba «por pasto común» entre los pobladores de Xarana y Quincena ${ }^{82}$.

Tresarna (Lebrija). En el amojonamiento de 1274 se puso un mojón en una cabeza en el "término de Tresarna»"

Chisterna (Lebrija). Localizada en el cerro del Donato en las proximidades de la marisma de Montegil. En 1414 una vecina de Lebrija vendía la haza de los Donatos a Fernando de Zurita ${ }^{84}$.

Grija (Lebrija). Situada en el cerro de Grija junto a la marisma de El Cuervo y en el camino hacia el donadío de Montegil. Desde 1522 el contador Juan López de Recalde fue adquiriendo tierras en el cortijo de Grija. Durante las primeras décadas del XVI se localizó un despoblado en unas tierras labrantías donde se hallaron «muchos pedaços grandes de ladrillos, tinajas y tejas por la dicha tierra labrada» ${ }^{85}$.

El Cuervo y Tollos (Jerez). Desarrollo su evolución en el último epígrafe.

Grañina (Jerez). Situada en un cerro en la sierra de Gibalbín. En 1264 se repartieron tierras entre diez pobladores jerezanos. En 1274 se alude al término de la aldea de Grañina ${ }^{86}$.

Gratutina (Jerez). Junto al molino del Cubo, actual cortijo del Cubo, al pie del cerro del Guijo. En las primeras décadas del xvi se localizaron «muchas piedras labradas y tejas y cimientos de casas a manera de auer allí población». Los restos estaban junto a unas salinas y el camino que la unía a Lebrija. Se justificó que «si agora [el camino] no va derecho al dicho villar de Gratutina es por la diuturnidad de tiempo que ha que está despoblada y no auer para qué vaya el dicho camino al dicho villar ${ }^{87}$.

Carrizal (Lebrija). Ubicada en las proximidades de la sierra de Gibalbín. En 1274 se alude al término de la aldea de Carrizal, «ó se parten los términos entre Xeres, Arcos e Lebrixa ${ }^{88}$.

Aunque el objetivo de esta investigación no es profundizar en el poblamiento, sí es necesario plantear de forma breve dos consideraciones en torno a la jerarquía de la red rural en los momentos previos a la conquista y a su evolución durante el siglo XIV.

En 1274 Tresarna, Grañina y Carrizal poseían sus propios términos. Ya que las alquerías no solían tener límites fijos, es probable que se aludiese a la delimitación de las aldeas incluidas en los repartimientos de Jerez y Lebrija. Esto significa que el

81 Abellán Pérez, Juan. El Cádiz islámico a través de sus textos. Cádiz: Universidad, 1996, p. 78.

82 González Jiménez, Diplomatario andaluz, pp. 440-443. AMJF, Allegatio ivris, s/f. Aguilar Moya, Laureano. "Jerez islámico». En Caro Cancela (coord.), Historia de Jerez de la Frontera, pp. 193-256, esp. p. 242.

83 GonzÁlez Jiménez, Diplomatario andaluz, pp. 440-443.

84 AMJF, Allegatio ivris, s/f.

85 Franco Silva, Alfonso. «Las inversiones de Juan López de Recalde, contador mayor de la Casa de la Contratación». En González Jiménez, Manuel (ed.). I Jornadas de Historia de Lebrija. Edad Media. Lebrija, 28-30 de octubre de 2004. Lebrija: Ayuntamiento y Universidad de Sevilla, 2005, pp. 101-162, esp. pp. 119 y 123. AMJF, Allegatio ivris, s/f.

86 González Jiménez, Diplomatario andaluz, pp. 440-443. Martín Gutiérrez, Emilio. "Aproximación al repartimiento rural en Jerez de la Frontera: la aldea de Grañina». En la España Medieval, 1999, vol. 22, pp. 355-368, esp. p. 368.

87 AMJF, AHR, Amojonamiento Jerez Lebrija, ańo 1434, s/f. AMJF, Allegatio ivris, s/f.

88 González Jiménez, Diplomatario andaluz, pp. 440-443. 
EMILIO MARTÍN GUTIÉRREZ

INTERACCIÓN SOCIEDAD Y MEDIO AMBIENTE. EL ENTORNO DE LA LAGUNA DE LOS TOLLOS

(ANDALUCÍA OCCIDENTAL), SIGLOS XIII AL XV

documento de 1274 muestra un poblamiento rural que ya había sufrido una primera alteración. Según Pierre Guichard las alquerías incluían conjuntos homogéneos de casas y tierras que dependían de varios propietarios o de una comunidad de agricultores ${ }^{89}$. Esos complejos cubrían «las necesidades diarias del campesinado» y su localización dependía de la "presencia de acuíferos que permitiesen la creación de espacios irrigados $»^{90}$.

Dejando a un lado el debate en torno al binomio hisn-alquería focalizado en el área mediterránea y en el Magreb, ese modelo no se ha aplicado en el Bajo Guadalquivir $y$ en la campiña jerezana ${ }^{91}$. La documentación escrita no permite profundizar en esta problemática -más allá de la elaboración de un listado de alquerías- y deja aún interrogantes sin resolver: ¿̇mantenían esas alquerías su vinculación con Jerez y Lebrija como así se observa tras la conquista castellana?, ¿qué papel desempeńó el hisn ubicado en la sierra de Gibalbín?, ¿¿cuál fue la interacción de esas comunidades campesinas con el medio?, ¿cuál fue la organización del paisaje rural?

La segunda consideración, e imbricada con la anterior, se centra en los despoblados ${ }^{92}$. Exceptuando los diez pobladores que recibieron tierras en Grañina en 1269, se desconoce su número en las restantes aldeas. El abandono de algunos núcleos rurales y el reagrupamiento de la población fueron la tónica en Andalucía Occidental. A esa tendencia detectada desde finales del XIII hay que añadir los efectos de la crisis del xiv en este espacio geográfico, aunque, hasta ahora, tan solo puedan ser intuidos ${ }^{93}$.

Del listado de alquerías del año 1274 del entorno de la laguna de los Tollos solo El Cuervo se mantuvo como núcleo poblado hasta el Xv. ¿Qué incidencia tuvieron los

89 Guichard, Pierre. «Le problème des structures agraires en al-Andalus avant la conquête chrétienne». En Cabrera Muñoz, Emilio (coord.). Andalucía entre Oriente y Occidente 1236-1492. Actas del V Coloquio Internacional de Historia Medieval de Andalucía. Córdoba: Diputación Provincial, 1988, pp. 161-170. Su significado como lugar poblado en Vejer, en Bustamante, «Topografía de las aldeas», p. 275.

90 Así, citando a Cressier, Thomas Glick resume las características de esa jerarquía: «defensa y protección en el castillo, religión (en una o varias mezquitas), agricultura (un sistema de riego vinculado a una o más alquerías). Los espacios intersticiales, dedicados a usos ganaderos, cultivos de cereales y la explotación forestal o de otros recursos naturales, complementan el complejo central»; GLICK, Paisajes de conquista, pp. 41-53. La presencia del agua ha ayudado a la localización de algunas alquerías en la campińa jerezana como Margalihud y al-Husayn. AbelLán Pérez, Juan. «Aproximación al espacio rural jerezano en la Edad Media: la alquería de Margalihud». Al-Andalus Magreb, 1999, vol. VII, pp. 13-20. ÍDEm. «Nuevos datos sobre la organización espacial del Jerez islámico: el pozo y la alquería de al-Husayn o Husayn». Qurtuba. Estudios andalusies, 2000, vol. 5, pp. 7-15.

${ }^{91}$ Puede seguirse el debate, con la bibliografía oportuna, en Martínez Enamorado, Virgilio. AlAndalus desde la periferia. La formación de una sociedad musulmana en tierras malagueñas (siglos VIII-X). Málaga: Diputación, 2003, pp. 249-265. Su aplicación en el Magreb central en Meouak, Mohamed. «Fortifications, habitats et peuplement entre Bougie et la Qal’a des Banu Hammad. Les données du géographe al-Idrisi (c.493/1100-c.560/1165)». Mélanges de la Casa de Velázquez, 2006, vol. 36, n. 1, pp 173-193.

92 En relación con los despoblados y «para superar la pura descripción nominal», Manuel González ya declaraba la necesidad de hacer arqueología. GonZÁLEZ JiMÉNEZ, La repoblación, p. 35.

93 Bors, Guy. La gran depresión medieval. El precedente de una crisis sistémica. Valencia: Universidad, 2001. La incidencia de esta crisis en Andalucía, en Borrero Fernández, Mercedes. «El mundo rural y la crisis del siglo xiv. Un tema historiográfico en proceso de revisión». Edad Media. Revista de Historia, 2007, vol. 8, pp. 37-58, esp. pp. 52-55. VILLALONGa SERrano, José Luis. Las estructuras agroganaderas de la campiña sevillana a finales de la Edad Media. El caso de Utrera. Sevilla: Diputación, 2008, pp. 27-48. 
EMILIO MARTÍN GUTIÉRREZ

INTERACCIÓN SOCIEDAD Y MEDIO AMBIENTE. EL ENTORNO DE LA LAGUNA DE LOS TOLLOS

(ANDALUCÍA OCCIDENTAL), SIGLOS XIII AL XV

MAPA 2.- Aldeas repartidas en 1269.

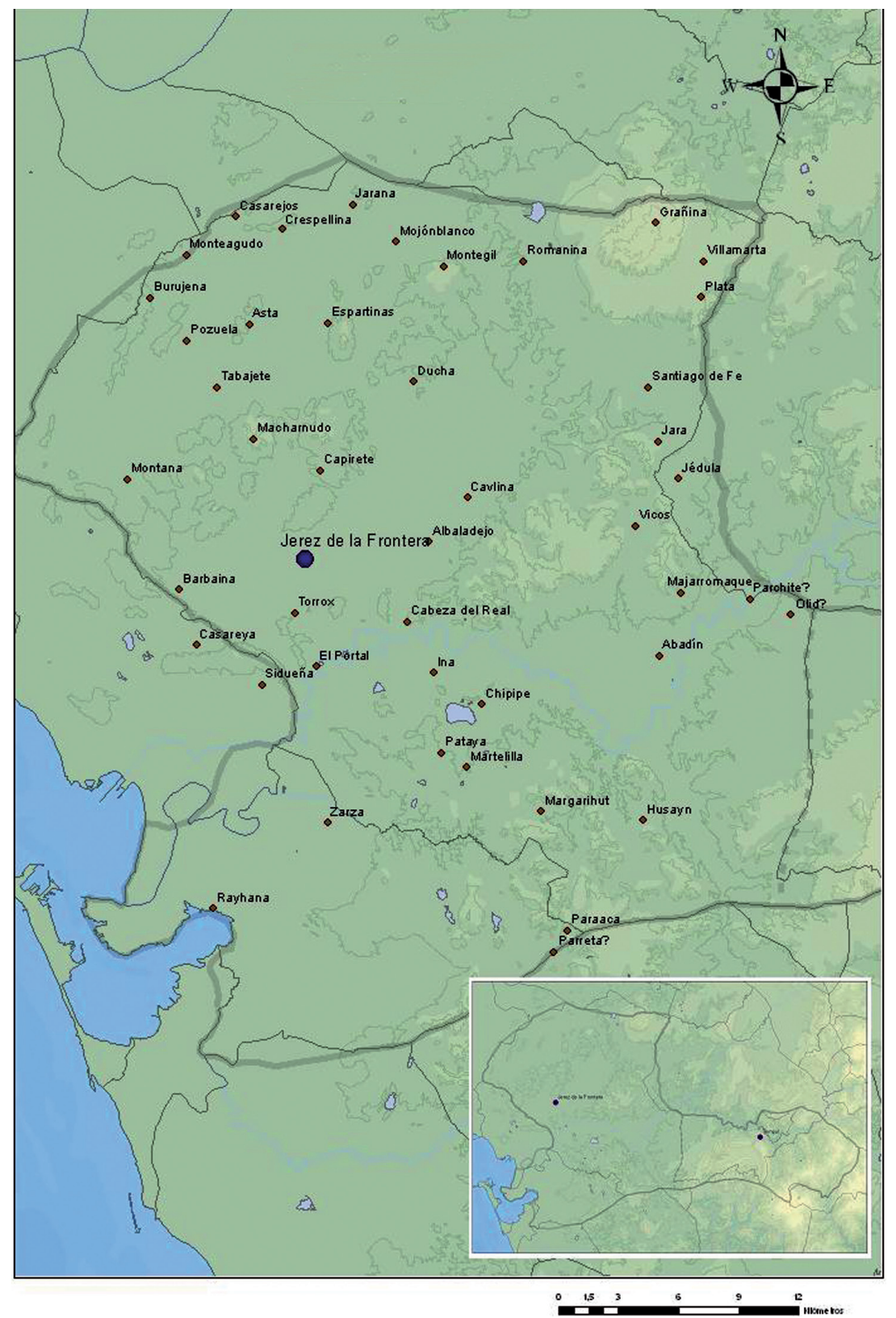

(C) Seminario Agustín de Horozco de estudios económicos de Historia Antigua y Medieval <http://agustindehorozco.uca.es/>. 
EMILIO MARTÍN GUTIÉRREZ

INTERACCIÓN SOCIEDAD Y MEDIO AMBIENTE. EL ENTORNO DE LA LAGUNA DE LOS TOLLOS

(ANDALUCÍA OCCIDENTAL), SIGLOS XIII AL XV

despoblados en los paisajes rurales en ese espacio durante el XIV? Aunque las tierras agrícolas no estuviesen plenamente explotadas y los niveles demográficos fuesen muy bajos, las comunidades campesinas se aprovecharon de los recursos de las marismas, ríos y lagunas así como de la caza y recolección en los montes. A lo que hay que sumar las actividades pecuarias que dejó su impronta en el paisaje. El valor del agua como recurso se mantuvo, como se tratará de explicar en las siguientes páginas.

En definitiva, si se centra la atención exclusivamente en los procesos roturadores, quedan difuminados otros aprovechamientos que también fueron relevantes entre los campesinos del entorno de la laguna de los Tollos como se ha comprobado en la Marisma durante el $\mathrm{xv}^{94}$.

\subsection{El aprovechamiento de los recursos hidricos: pozos, fuentes, tollos y lagunas}

En el Mediterráneo los agentes del poder feudal buscaron controlar los recursos hídricos. El territorio de Siena, según Duccio Balestracci, «è inoltre caratterizzato - per lo meno fino al secondo Settecento- da vaste aree a palude» en la Maremma, Val di Chiana o Orgia. Desde el XIII «le acque di questo territorio subiscono una vera e propria politica di aggressione e di domesticazione portata avanti, in tempi diversi, con mezzi diversi, individualmente o di concerto, da una serie di soggetti: Siena, enti ecclesiastici, aristocratici, comunità» ${ }^{95}$.

María Isabel del Val ha analizado la consideración del agua como bien público -al igual que ocurría en otras regiones europeas, como Francia e Italia- en la corona de Castilla ${ }^{96}$. Ese punto de partida enmarcaba las acciones jurídicas desde donde dilucidar los conflictos.

Las cosas que comunalmente pertenecen todas las criaturas que biuen en este mundo son estas, el ayre, et las aguas de la lluuia et el mar et su ribera. Ca qualquier criatura que biua, puede vsar de cada vna destas cosas, según quel fuere menester. Et por ende todo ome se puede aprouechar de la mar et de su ribera, pescando et nauegando et faziendo y todas las cosas que entendiere que a su pro son ${ }^{97}$.

Junto a los ríos, el derecho local fue incluyendo algunas fuentes y pozos entre los comunales, elaborándose una normativa especial. El acceso se realizaba mediante caminos y veredas que debían ser públicos. Las ordenanzas municipales reglamentaron el aprovechamiento de pozos y fuentes que habían sido construidos, previa autorización del concejo, en terrenos privados y para uso exclusivo de sus propietarios ${ }^{98}$.

94 Borrero Fernández, La acción del hombre sobre el medio natural, pp. 434-436.

95 Balestracci, Duccio. "L'uso delle acque interne nel Senese nel Medioevo». En Malvolti e Giuliano (a cura di), Incolti, fiumi, paludi, pp. 117-141.

96 Val Valdivieso, Agua y poder, pp. 39-66. Carmona Ruiz, María Antonia. La ganadería en el reino de Sevilla durante la Baja Edad Media. Sevilla: Diputación, 1998, pp. 180-185.

97 Alfonso X, Las Siete Partidas. Partida III, Título XXVIII, Ley II, vol II, p. 155.

98 Bonachía Hernando, Juan Antonio. «El agua en las Partidas». En Val Valdivieso (coord.), Agua y sociedad en la Edad Media hispana, pp. 13-64. CARmona RuIz, La ganadería en el reino de Sevilla, pp. 180-185. 
EMILIO MARTÍN GUTIÉRREZ

INTERACCIÓN SOCIEDAD Y MEDIO AMBIENTE. EL ENTORNO DE LA LAGUNA DE LOS TOLLOS

(ANDALUCÍA OCCIDENTAL), SIGLOS XIII AL XV

Durante el siglo xv las ciudades y villas fueron delimitando sus términos y controlando sus propios recursos. Esas políticas expansionistas generaron conflictos entre las localidades vecinas. Evidentemente el acceso del ganado a los abrevaderos era esencial. En todos los términos concejiles se arbitraron fórmulas para permitir su entrada sin causar daños en los cultivos, lo cual no evitaba las disputas entre concejos y particulares ${ }^{99}$. Un ejemplo fue el pleito entre Lebrija y Utrera, entre 1531 y 1535, estudiado por María del Mar García. Aunque no se ha conservado el proceso completo, la sentencia dictada en 1535 diferenciaba los aprovechamientos. Aun reconociendo que la villa de Lebrija estaba incluida a todos los efectos en la Tierra de Sevilla, el concejo había construido o adquirido los pozos formando parte de sus bienes de propios. Amparándose en esa casuística, Lebrija podía protegerlos durante el verano. Diferente era la situación de los tollos. Aunque argumentaba que su aprovechamiento se regulaba por «la costunbre que se ha tenido de tiempo inmemorial entre las dichas villas», la sentencia insistía en su aprovechamiento comunal, prohibiendo que se vetase su uso durante los meses estivales ${ }^{100}$.

Los problemas entre Jerez y Lebrija por los recursos hídricos fueron frecuentes. Fijada la linde en 1434, se ordenaba que pudiesen "paçer las yeruas y beber las aguas y cortar la leña y faser todas las otras cosas que en los otros sus términos suelen y pueden y deuen faser» ${ }^{101}$. Sin embargo, las agresiones continuaron y se reprodujeron las denuncias. Así, mientras que el ganado de Lebrija acudía a abrevar al pozo del jerezano Alvar López, construido «al canto de la laguna de Toyos», el de Utrera se dirigía a la Fuente del Cuervo y al pozo de los Tollos ${ }^{102}$.

Fue muy frecuente la presencia de lagunas comunales en tierras privadas. En esas ocasiones el propietario del donadío o de la dehesa estaba obligado a permitir el paso del ganado y de las personas hacia el humedal ${ }^{103}$. En 1540 se llegaba a un acuerdo entre el concejo de Jerez y el convento de la Madre de Dios por el que se abría una vereda que «fuese e quedase realenga e conçegil» entre la dehesa de los Tollos y la dehesa de los herederos de Eutropio Ponce de León, permitiendo «el paso de los ganados y gente de un realengo a otro» ${ }^{104}$.

\subsection{Entre marismas y humedales: aprovechamientos pastoriles y cinegéticos}

En 1274 se indicaba que las marismas debían ser aprovechadas por las comunidades de Jerez y Lebrija ${ }^{105}$. Si de la albina se obtenía sal, de la quema de los almajos recolectados ceniza para la fabricación de jabón. Mercedes Borrero ha analizado los contratos de venta de «çeniza de almarjo» en Lebrija. El proceso conecta su aprovechamiento y distribución

\footnotetext{
99 Val Valdivieso, Agua y poder, pp. 79-82.

100 García GuZmán, "Aprovechamientos ganaderos», pp. 173, 177 y 178.

101 AMJF, AHR, Amojonamiento Jerez-Lebrija, año 1434, s/f.

102 AMJF, Allegatio ivris, s/f.

103 Carmona Ruiz, La ganadería en el reino de Sevilla, pp. 182-185.

104 AMJF, AHR, Amojonamiento Jerez, Alcalá y Paterna, ańo 1526, fol. 112v.

105 GonzÁlez Jiménez, Diplomatario andaluz, pp. 440-443.
} 
EMILIO MARTÍN GUTIÉRREZ

124 INTERACCIÓN SOCIEDAD Y MEDIO AMBIENTE. EL ENTORNO DE LA LAGUNA DE LOS TOLLOS (ANDALUCÍA OCCIDENTAL), SIGLOS XIII AL XV

Mapa 3.- El entorno de la laguna de los Tollos (Siglos XIII al Xv).

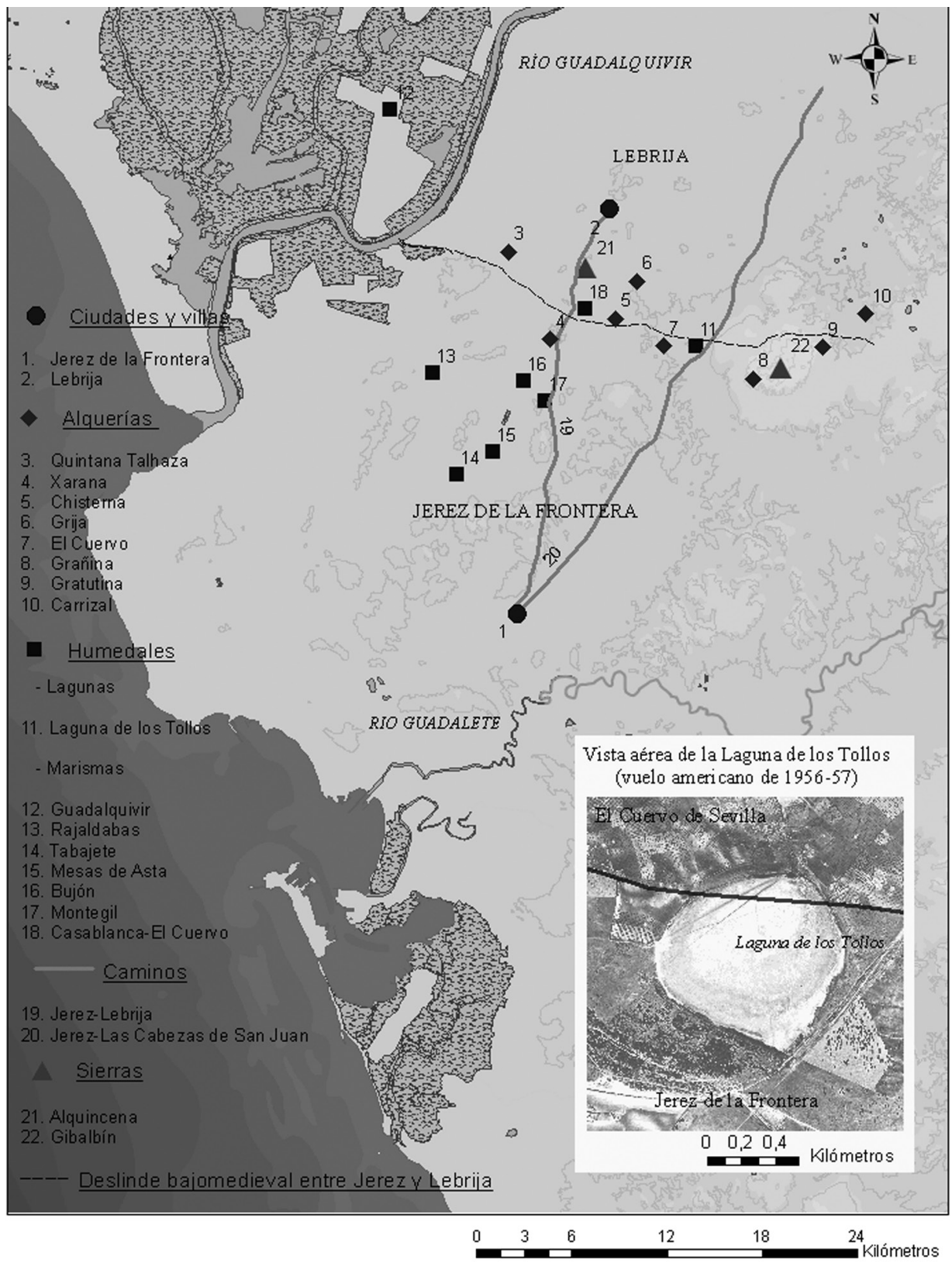

(C) Seminario Agustín de Horozco de estudios económicos de Historia Antigua y Medieval <http://agustindehorozco.uca.es/>.

(c) Ediciones Universidad de Salamanca

Stud. hist., H. ${ }^{a}$ mediev., 32, 2014, pp. 103-130 
EMILIO MARTÍN GUTIÉRREZ

INTERACCIÓN SOCIEDAD Y MEDIO AMBIENTE. EL ENTORNO DE LA LAGUNA DE LOS TOLLOS

(ANDALUCÍA OCCIDENTAL), SIGLOS XIII AL XV

a través de «la lengua de agua entre Ester de Cańas y Tarfía» con el mercado sevillano controlado por la familia genovesa de los Ripparolio a finales del xv. El campesinado lebrijano recogía los almajos durante el verano «cuando ya han terminado de recolectar el trigo de otros y aún no se les ha abierto el mercado de trabajo temporal del olivar» ${ }^{106}$. Esas labores marismeñas fueron habituales en épocas anteriores, aunque no hayan dejado un rastro documental.

La incidencia de la ganadería en la creación de paisajes -como es el caso de las dehesas- es bien conocida. Se han estudiado las comunidades de pasto, como la Hermandad creada por Alfonso X en 1269, que, aunque no llegó a cuajar, permite vislumbrar su aprovechamiento entre los campesinos de las localidades implicadas: pastos, leña y madera ${ }^{107}$. Una orientación pastoril que se fue intensificando durante los siglos XIV y XV. Si en la campiña jerezana las dehesas y echos se localizaban al sur y sureste de la laguna de Medina ${ }^{108}$, en las inmediaciones de los Tollos se ubicaban las dehesas de los Tollos, del Cuervo o la de Álvar López ${ }^{109}$.

Los humedales andaluces son vitales para el movimiento migratorio de las aves. Si el rey Alfonso XI narraba su pasión por la caza en la laguna de Medina ${ }^{110}$ o el canciller Pedro López de Ayala estudiaba el paso de las aves a través del Estrecho de Gibraltar ${ }^{111}$, el humanista Juan de Mal Lara anotaba las posibilidades cinegéticas de la marisma de

106 Borrero Fernández, Mercedes. «Lebrija en la Baja Edad Media. Población y economía». En GonzÁlez Jiménez (ed.), I Jornadas de Historia de Lebrija, pp. 81-100, esp. p. 96. María del Mar García se hace eco de las quejas de los criadores de ganado. Estos se oponían «porque los hoyos que hacían para quemar las plantas y recoger sus cenizas se cubrían de agua y caían en ellos los animales». La explotación fue prohibida por Lebrija en 1724. García Guzmán, Aprovechamientos ganaderos, p. 162.

107 Carmona Ruiz, María Antonia. «Ganadería y frontera: los aprovechamientos pastoriles en la frontera entre los reinos de Sevilla y Granada. Siglos XIII al xv». En la España Medieval, 2009, vol. 32, pp. 249-272. Gerbet, M. elaude. La ganadería medieval en la Península Ibérica. Barcelona: Crítica, 2002, pp. 192-193.

108 Martín Gutiérrez, La organización del paisaje, pp. 78-84.

109 AMJF, AHR, Cajón 11, n.o 29, Amojonamiento Jerez, Alcalá y Paterna, año 1526. El legajo incluye un anexo: Amojonamiento de la dehesa Laguna de los Tollos, año 1541, fols. 112r-121v. AMJF, Allegatio ivris, s/f.

110 «Et ese día fue el rey a posar a dos leguas de la villa allende Guadalete: et otro día fue posar cerca de la laguna de Medina et falló en aquella laguna muchos cisnes. Et porque él avía a esperar allí dos días los de la hueste que podiesen cargar sus viandas, et las otras cosas que avían de levar, entretanto mandó traer tres barcos pequeños para aquella laguna. Et el rey entró en el de un barco, et con él dos omes que remaban, et el que le armaba la ballesta ca él lanzaba muy bien con ella: et mandó entrar omes en los otros barcos, et corrió en pos aquellos cisnes fasta que tomó seis dellos vivos et mató quatro. Et esto cuenta la estoria, poque el rey cataba todo tiempo qué ficiese. Et partió de aquel logar et fue otro día allende de Medina Sidonia»; "Crónica de don Alfonso el Onceno", pp. 493-494.

111 «Muchas aves crían en esta tierra de Europa que contiene en Espańa, Françia e otras tierras. E quando viene el invierno pasan allende la mar en África porque es más caliente. E después el verano, tornasen. E yo vi por el Estrecho de Marruecos, que es entre Tarifa e Çepta, pasar las çigüeńas al cabo del verano que se tornaban para África, que tantas eran que non podía omne contarlas, que duravan grand trecho por el çielo, que iva la nuvada de ellas. E eso mesmo las garças e otras aves. E así dizen que lo fazen las codornizes, ca muchas vezes falla omne con un viento muchas de ellas e pues que otro viento viene parten de allí e vanse en este tienpo mucho"; López de Ayala, Pedro. Libro de la caza de las aves, ed. John Cummins. London: Tamesis Books, 1986, cap. XLV. 


\section{INTERACCIÓN SOCIEDAD Y MEDIO AMBIENTE. EL ENTORNO DE LA LAGUNA DE LOS TOLLOS \\ (ANDALUCÍA OCCIDENTAL), SIGLOS XIII AL XV}

Lebrija ${ }^{112}$. Esas descripciones se complementan con la documentación notarial. En 1513 cuatro lebrijanos llegaron a un acuerdo con gente de Sevilla para «darles todas las aves de marismas que nos todos quatro mataremos en las Rosinas». En ese año el arrendador del cazadero de Rodeo de Margalla se comprometía a vender anticipadamente "cuanto se caçe» de lavancos y ánades a 15 maravedíes, picolados y patos nuevos a 9 y «çerçetas» a $6^{113}$.

Estas actividades aluden a humedales no muy alejados de El Cuervo. No es difícil relacionarlas con la laguna de los Tollos máxime si se tiene en cuenta la biodiversidad de la fauna que la habita, entre la que destacan las poblaciones de aves acuáticas. Estas siguen constituyendo el grupo faunístico más relevante a pesar de los cambios que han experimentado a lo largo del tiempo, como consecuencia de la evolución del humedal, habiendo llegado a registrarse la presencia de hasta seis especies en peligro de extinción ${ }^{114}$. Un hombre de sesenta años de edad aseguraba que había un carril que se dirigía desde Lebrija al donadío del Molino del Cubo y de allí ascendía hacia el cerro de Grañina en la sierra de Gibalbín. Conocía el camino porque lo había «visto y andado muchas vezes en todo el dicho tiempo yendo a caça y a monte y a guardar las cuadrillas de moros» ${ }^{115}$.

La regulación de las actividades cinegéticas restringió el uso de zonas que poseían valor económico: bosques y montes, fundamentalmente. Y, al igual que en otras comarcas, durante el siglo xv la ciudad de Jerez fue ordenando la caza menor e incluyendo su normativa en las ordenanzas municipales ${ }^{116}$.

\subsection{El Cuervo: de poblado a donadio y dehesa}

Desde finales del XIv hay indicios razonables para pensar que los niveles demográficos se fueron invirtiendo. Durante el xv hubo un aumento en la producción cerealista suficiente para alimentar a una población cada vez mayor y para afrontar las crisis agrarias. Las investigaciones muestran el trabajo de los campesinos como una pieza en un sistema equilibrado entre agricultura y ganadería en el que el mercado fue adquiriendo mayor relevancia ${ }^{117}$.

112 Hay «una albina que es un lago grande en que hay innumerable cantidad de aves de agua, patos negros, blancos y de otros colores, que por el mes de julio van a desovar en unos altos eneales que allí se hacen y entran con barcos a caza de ellos y córrenlos de manera que matan a palos grande número de ellos. Hay otros mil géneros de aves de marismas». Este texto en Caro Bellido y Tomassetti Guerra, Antonio de Nebrija, p. 56.

113 Borrero Fernández, Lebrija en la Baja Edad Media, p. 97.

114 Tarro canelo, cerceta pardilla, porrón pardo, focha moruna, fumarel común y malvasía cabeciblanca explotaban la laguna de forma habitual hace décadas. Tras la transformación sufrida a consecuencia de la actividad minera, solo algunas de ellas se presentan ocasionalmente en el humedal. Humedales de Cádiz: veinte años de conservación. CAPMA (CMAOT) 2009.

115 AMJF, Allegatio ivris, s/f.

116 Ladero Quesada, Miguel Ángel. «La caza en la legislación municipal castellana. Siglos XIII al xviII». En la España Medieval. Estudios dedicados al profesor D. Julio González, 1980, vol. 1, pp. 193-221. Carmona Ruiz, María Antonia y Martín Gutiérrez, Emilio (eds.). Recopilación de las ordenanzas del concejo de Xerez de la Frontera. Siglos XV-XVI. Cádiz: Universidad, 2010, pp. 172-176.

117 Borrero Fernández, La acción del hombre, p. 419. 
EMILIO MARTÍN GUTIÉRREZ

INTERACCIÓN SOCIEDAD Y MEDIO AMBIENTE. EL ENTORNO DE LA LAGUNA DE LOS TOLLOS

(ANDALUCÍA OCCIDENTAL), SIGLOS XIII AL XV

En 1431 María Fernández, viuda de Juan Gutiérrez, donaba al regidor jerezano Fernando Alfonso de Zurita unas tierras que «son con la dicha Fuente del Cuervo en el aldea de Toyos» en el término de Jerez ${ }^{118}$. Con toda probabilidad esta denominación aluda al mismo poblado nombrado en el deslinde de 1274. Su entidad debió ir menguando hasta convertirse en un despoblado, mientras que la ciudad de Jerez se fue convirtiendo en el centro rector de la campińa y la villa de Lebrija fue adquiriendo mayor solidez ${ }^{119}$. Ese abandono se fue acelerando durante las primeras décadas del xvi: algunos testigos encontraron «muchas piedras a manera de población». Pero esas afirmaciones se contradecían con otras que sostenían que el «derramamiento de piedras no fue ni ha sido villar [...] salvo que vn vezino de Lebrixa hizo allí vnas çahurdas de piedra seca. Y que de las dichas çahurdas que se desbarataron es el dicho derramamiento de piedras y que nunca fue villar ${ }^{120}$. Declaraciones contradictorias que no ocultaban su paulatino abandono. Por esos mismos ańos Lebrija defendía el uso de sus pozos incluyendo la Fuente del Cuervo y el Pozo de los Tollos.

Durante el XV y XVI varios propietarios tuvieron sus fincas en el donadío de El Cuervo en el término jerezano. En la segunda mitad del xv Hernando de Medina Villavicencio fue propietario del donadío de El Cuervo. El linaje de Medina tuvo un gran protagonismo en Jerez entre las últimas décadas del XIV y finales del $\mathrm{xv}^{121}$.

La presencia de la familia Zurita se hacía efectiva con la donación de María Fernández. El 4 de septiembre de 1431 el regidor jerezano Fernando Alfonso de Zurita recibía seis caballerías de tierras, alrededor de 180 hectáreas, en la Fuente del Cuervo en la aldea de Tollos, «para pan sembrar e pastos, con sus aguas e posos manantes e corrientes e estantes» ${ }^{122}$. Posteriormente, el 23 de julio de 1448, Fernando Alonso donaba a su hijo, y también regidor, Diego Fernández de Zurita tres lotes de tierras. Una de esas hazas estaba en los Tollos, en la viña del Cuervo y de Vivanco ${ }^{123}$.

El 1 de noviembre de 1483 Teresa de Zurita -hija de Fernando Alfonso de Zurita y mujer del veinticuatro cordobés Pedro de los Ríos- vendía 600 aranzadas, unas

118 Agradezco a Enrique Ruiz Pilares esta información que verá la luz en un próximo artículo. El documento está en Archivo del Marqués de Campo Real, sin catalogar, ascendencia Zurita.

119 Juan López Ricarde compraba la mitad del donadío del Gamoso. La apuesta de la oligarquía lebrijana por el olivar fue determinante en la gestación del paisaje rural. Franco Silva, «Las inversiones de Juan López Ricalde», p. 109. Borrero Fernández, «Lebrija en la Baja Edad Media», pp. 90-92. AMJF, Allegatio ivris, s/f. En relación con Jerez, Martín GutiÉrrez, La organización del paisaje, pp. 158 y $161-162$.

120 González JimÉnez, Diplomatario andaluz, pp. 440-443. AMJF, AHR., Amojonamiento JerezLebrija, año 1434, s/f. AMJF, Allegatio ivris, s/f.

121 SÁnchez Saus, Linajes medievales, (vol. I), p. 115.

122 Linderos: tierras de Isabel Fernández de Zurita, tierras de Juan Sánchez de Vivanco, tierras de Fernando Alfonso de Zurita, el padrón de Lebrija, el padrón de Jerez, las tierras realengas y el arroyo y padrón de Romanina. Archivo del Marqués de Campo Real, sin catalogar, ascendencia Zurita.

123 La superficie de la haza era de 20 aranzadas, 10 hectáreas. Linderos: tierras del regidor Fernando Alonso de Zurita, tierras de Juana Fernández, viuda de Lorenzo Fernández de Villavicencio, la marisma de Montegil, el arroyo de Romanina y Badalejo. El resto de la donación en la Cabeza del Algar (10 aranzadas) y en Montegil (20 aranzadas). AMJF, Protocolos Notariales, año 1448, Escribano Antón Franco, fol. 94v. 
EMILIO MARTÍN GUTIÉRREZ

INTERACCIÓN SOCIEDAD Y MEDIO AMBIENTE. EL ENTORNO DE LA LAGUNA DE LOS TOLLOS

(ANDALUCÍA OCCIDENTAL), SIGLOS XIII AL XV

300 hectáreas, a Eutropio Ponce de León ${ }^{124}$. La heredad incluía edificaciones -casas y palomares ${ }^{125}$-, zonas cultivadas -tierras de pan, viñas y arboledas-, espacios de montes y pastos y las «aguas corrientes e estantes e manantes» ${ }^{126}$.

En su testamento de 17 de noviembre de 1510, Eutropio Ponce de León incluía esta propiedad y 15 cahíces de renta de "pan terçiados» como lote para que fuese heredado por su hijo Francisco Ponce de León y Trujillo, vástago de su segunda esposa Marina de Trujillo ${ }^{127}$. En las primeras décadas del xvi se recordaba la usurpación que había efectuado de una parte del camino que discurría en las inmediaciones ${ }^{128}$.

En 1504 se documenta la primera referencia al convento de monjas clarisas de la Madre de Dios en Jerez. Entre las tierras que el convento poseía se encontraba el donadío y dehesa de Tollos en las inmediaciones de la Fuente de los Tollos en el término jerezano. Aunque desconozco su forma de adquisición y superficie, es muy probable que su situación coincida con el actual topónimo cortijo de las Monjas al norte de El Cuervo. Entre el 17 de diciembre de 1540 y el 8 de febrero de 1541se deslindaba una vereda -entre la dehesa del convento de la Madre de Dios y la dehesa de El Cuervo de los herederos de Eutropio Ponce de León- que iba desde la marisma realenga hasta el término realengo. En su recorrido se describía el valladar de las viñas de El Cuervo, la casa de la Dehesa del Cuervo y el pozo de la Horca en la marisma realenga ${ }^{129}$.

\section{Conclusiones}

Iniciaba el artículo con las palabras de Domingo Ruiz y con la lectura del libro de Harald Welzer. Aunque pudieran parecer dos referencias inconexas, el punto de unión

124 Eutropio Ponce de León contrajo matrimonio con Catalina de Vera, hija de Pedro de Vera y Juana de Zurita. Hijo de don Juan Ponce de León, II conde de Arcos, recibió como herencia paterna un patrimonio valorado en 200.000 maravedíes que hubo de venderse para comprar «el gran donadío de El Cuervo, cabeza del posterior marquesado de ese nombre»; Sánchez SAus, Linajes medievales, (vol. I), pp. 148-149. Devís Márquez, Federico. Mayorazgo y cambio político. Estudios sobre el mayorazgo de la Casa de Arcos al final de la Edad Media. Cádiz: Universidad, 1999, pp. 32 y 38-39. El propietario se la había comprado a una vecina de Lebrija en 1414. AMJF, Allegatio ivris, s/f.

125 El estiércol de los palomares «es muy bueno y de mucho precio para la labor del campo mayormente de huertas y para muchas medicinas»; Herrera, Obra de Agricultura, p. 316.

126 El precio fue fijado en 253.100 maravedíes. Linderos: tierras de Nuño de Villavicencio, tierras de Mirabal, tierras de Juan de Medina, el donadío de los Donatos y las tierras realengas. Sobre Teresa de Zurita, SÁnchez SAus, Linajes medievales (vol. I), p. 233.

127 Linderos: el padrón de Lebrija, tierras de los herederos de Juan de Medina y tierras de los herederos de Nuño de Villavicencio. AMJF, PN, año 1510, fols. 6-192. Sánchez SAus, Linajes medievales, (vol. I), pp. 147 y 148-149. En 1522, Eutropio Ponce de León y su mujer vendían al veinticuatro Luis Ortiz de Gática 2.000 maravedíes de censo y tributo perpetuos en el donadío de El Cuervo -con tierras de cereal, vińas, huertas y palomar- con una superficie de 11 caballerías. Linderos: tierras de los herederos de Juan de Medina, tierras de Nuño de Villavicencio y el padrón de Lebrija. AMJF, Protocolos Notariales, Escribano Luis de Llanos, fols. 234r-236v.

128 AMJF, Allegatio ivris, s/f.

129 Para realizar el deslinde de la vereda se tomaron 4,5 aranzadas de la dehesa de los Tollos y 3,5 de la dehesa de El Cuervo. AMJF, AHR, Cajón 11, n. ${ }^{\circ}$ 29, Amojonamiento Jerez, Alcalá y Paterna, año 1526. El legajo incluye el anexo: El amojonamiento de la dehesa Laguna de los Tollos, año 1541, fols. 112r-121v. 
EMILIO MARTÍN GUTIÉRREZ

INTERACCIÓN SOCIEDAD Y MEDIO AMBIENTE. EL ENTORNO DE LA LAGUNA DE LOS TOLLOS

(ANDALUCÍA OCCIDENTAL), SIGLOS XIII AL XV

está en los conflictos por el control del agua. El 5 de septiembre de 1494 el comendador Eutropio Ponce de León denunciaba que «çiertos omes a caballo e a pie, vesinos de Lebrija», habían ido al donadío de El Cuervo a la sazón arrendado a Cristóbal de Villanueva.

Allí «le quebraron çiertas pilas que estavan en la fuente en que venían con sus ganados». Añadía que "asý mismo fueron a las casas e caserío que tiene en el dicho donadío e derribaron vna esquina. E que el casero, que allí estava, les dijo que no lo fisiesen, que aquello era término desta çibdad».

Obtuvo como respuesta un ultimátum: «que para otro día sacase todo que dentro tenía en la dicha casa sy non que avían de venir e la avían de derribar». Su relato finalizaba acusando a un miembro del cabildo jerezano: «vn caballero desta çibdad dió consejo a los de Lebrija para que fisiesen lo que han hecho». Aquel ataque a sus propiedades no podía tener una solución consensuada. Y aunque reconocía que sabía "quién es el cavallero» prefería guardar silencio «porque él lo entiende quejar a sus altesas e fuera del dicho cabildo» ${ }^{130}$. Trescientos años después, el historiador jerezano Bartolomé Gutiérrez relataba esos incidentes. Sostenía que «tan irritados estaban los capitulares» que algunos -Álvar López, Diego González de Gallegos y Francisco de Villacreces- arguyeron que, «si necesario fuese ir de mano armada contra ellos, ellos y los suyos estaban prestos para defender los fueros de la ciudad» ${ }^{131}$.

El control de los recursos hídricos era, y es, un asunto de vital trascendencia. Como se ha podido comprobar a lo largo de estas páginas, resulta de especial relevancia el aprovechamiento de pozos, fuentes, tollos o lagunas y la conflictividad generada por su control entre los diferentes agentes de poder. Los pleitos entre Lebrija y Utrera o entre Jerez y Lebrija son ejemplos significativos de esta problemática.

A través del estudio de los humedales hemos analizado la interacción de la sociedad con el medio ambiente durante los siglos XIII al xv. La constatación de que el paisaje no es una realidad estática sino que se encuentra en constante cambio, permite la reflexión en torno a las transformaciones acaecidas en el Bajo Guadalquivir y su incidencia en las marismas del norte del término de Jerez y en el Guadalete.

En el entorno de la laguna de los Tollos, ubicada al suroeste de la depresión del Guadalquivir, el agua y las marismas desempeñaron un papel significativo. Las comunidades campesinas supieron aprovecharse de sus posibilidades y de sus recursos: las actividades pecuarias y cinegéticas.

También hemos analizado la evolución del poblamiento rural en un momento decisivo como fue la conquista castellana en 1264. No se debe olvidar que este espacio cuenta con un poblamiento secular que hemos subrayado durante nuestra investigación. La sierra de Gibalbín constituye desde ese punto de vista una atalaya muy interesante para conocer la evolución de los núcleos rurales de ese espacio.

La evolución de El Cuervo entre el xiI y el xv es un caso paradigmático. Desde finales del siglo XIV parece que sus niveles demográficos fueron menguando hasta desaparecer como núcleo poblado. Durante el siglo Xv y el Xvi el donadío del Cuervo estuvo en

130 AMJF, AC, 1494, fol. 151v.

131 Gutiérrez, Bartolomé. Historia de Xeres de la Frontera. 2 vols. Jerez, 1989, vol. II, p. 312. 
manos de diversos propietarios jerezanos como la familia de Hernando de Medina de Villavicencio o el monasterio de monjas clarisas de la Madre de Dios en Jerez. Pero, en cualquier caso, fue la familia Zurita la que ha dejado un rastro documental que permite conocer las diferentes partes de esta heredad: edificaciones como casas y palomares, zonas cultivadas que incluían tierras de pan, vińas y arboledas y espacios de montes y pastos con sus correspondientes recursos hídricos.

En definitiva, en nuestro estudio planteamos una línea de investigación que viene dando sus frutos, como lo atestiguan las aportaciones bibliográficas vinculadas a la historiografía italiana, francesa, inglesa y española. El modelo de microhistoria ambiental se antoja, por tanto, una vía adecuada para profundizar en el conocimiento de los paisajes rurales. Su aplicación, en cualquier caso, no ha impedido la comparación con otras zonas del área mediterránea. 